\title{
About the correlation between the mobility of a polyion and that of its counterions
}

\author{
Anis. GHAZOUANI, Sondes. BOUGHAMMOURA, Jalel. M'HALLA* \\ Faculty of Sciences of Monastir, UR « Electrolytes» \\ University of Monastir, 5000 Monastir, Tunisia \\ *Email: jalel.mhalla@fsm.rnu.tn
}

\begin{abstract}
In this paper, we propose a new approach in order to interpret the variation of the conductibility of the PSS polyion with the nature and the concentration of the alkaline counter-ions $\mathrm{Li}^{+}, \mathrm{Na}^{+}$and $\mathrm{K}^{+}$, and the hydrophobic cations $\mathrm{Et}_{4} \mathrm{~N}^{+}$and $\mathrm{Bu}_{4} \mathrm{~N}^{+}$. This approach is based on a recent model in which the stretched polyion is represented by a chain of successive charged spheres, partially condensed by the counter-ions. We have found that the moderate variation of the hydrodynamic friction on the polyion with the size $\mathrm{R}_{\mathrm{M}}$ of condensed counter-ions, cannot completely explain the important decrease (of about $35 \%$ from $\mathrm{K}^{+}$to $\mathrm{Bu}_{4} \mathrm{~N}^{+}$) of the conductibility $\left(\lambda_{\mathrm{PSS}, \mathrm{M}}\right)$ of the PSS polyion with the nature of the counter-ions. Consequently, we have proposed a supplementary explanation by taking into account of the translational dielectric friction on the moving polyion. Formal analysis of this friction shows that it is very sensitive to the local structure of water surrounding the polyions. As this local structure depends in its turn, on the nature of the condensed counter-ions; we suggested that this specific sensitivity could explain the high dependence of the mobility of the polyion with the nature of its counter-ions.
\end{abstract}

\section{Keywords}

Conductibility; Ionic condensation; Polystyrene sulphonate; Ionic friction; Dielectric friction; Hydrophobic.

\section{Academic Discipline}

Physical chemistry.

\section{SUBJECT CLASSIFICATION}

Polyelectrolytes.

\section{TYPE (METHOD/APPROACH)}

A research paper on empirical and theoretical interpretations of experimental conductibility of some polyelectrolytes.

\section{Council for Innovative Research}

Peer Review Research Publishing System

\section{Journal: Journal of Advances in Chemistry}

\author{
Vol. 10, No. 4 \\ editorjaconline@gmail.com




\section{INTRODUCTION}

Contrary to the case of the simple electrolytes, the conductivity of poly electrolytes does not obey to a universal linear limiting law relating their equivalent conductivity at high dilution to the square root of ionic strength: $1^{1 / 2}$. Consequently, there is no currently available satisfactory theory describing the dynamic behavior of dilute flexible polyelectrolytes in aqueous solution despite some interesting progress toward this objective [1-10]. This difficulty arises from the complex interdependence between polyion conformation, the processes of condensation of counter-ions $\mathrm{M}^{+}$, the ionic screening effect and frictional effects.

In a series of previous papers [11-13], H. Vink proposed a semi- empirical approach for the interpretation of the conductivity of some polyelectrolytes, in order to: a) verify the Manning's theory $[3,8]$ and: b) to study the dependence of the conductibility of some polyions with the nature of their counter-ions. The main results of these studies concerning dilute MPSS polyelectrolyte solutions are:

- The degree of condensation (1- $\alpha)$ of counter-ions is practically independent as well as of the concentration and of the nature of studied counter-ions $\mathrm{Li}^{+}, \mathrm{Na}^{+}$and $\mathrm{K}^{+}$, and that its value $(0.65)$ is very close to that predicted by the theory of Manning. However, for organic counter-ions $\left(\mathrm{Et}_{4} \mathrm{~N}^{+}\right.$and $\left.\mathrm{Bu}_{4} \mathrm{~N}^{+}\right)$, $\alpha$ is in general slightly lower than that of the Manning value $\alpha^{\text {Manning }}$

- The ionic friction coefficient on the polyion $\left(\beta_{i r}\right)$ can be assumed to be equal to that predicted by the Manning's theory.

The experimental conductibility $\lambda_{P, M}$ of the PSS polyion depends strongly on the nature of the counter-ion $\mathrm{M}^{+}$in a range of concentration between $510^{-4} \mathrm{M}$ and $3.510^{-3} \mathrm{M}$. Indeed, by combining the experimental equivalent conductivities $\Lambda_{\mathrm{MP}}{ }^{\exp }$ with their corresponding experimental "transference numbers", TP,M , the author has been able to extract for each type of counter-ions and for a given concentration, the conductibility $\lambda_{P, M}$ of the PSS polyion and he has found that $\lambda_{P, M}$ increases with the mobility of the counter-ions in accordance with the following order: $\mathrm{M}^{+} \equiv \mathrm{H}^{+}, \mathrm{Li}^{+}, \mathrm{Na}^{+}, \mathrm{K}^{+}, \mathrm{Et}_{4} \mathrm{~N}^{+}$and $\mathrm{Bu}_{4} \mathrm{~N}^{+}$.

However, this last result is qualitatively and quantitatively in complete contradiction with the Manning's theory for which both the degree of condensation (1- $\alpha$ ) and the conductibility $\lambda_{P, M}$ of the PSS polyion are independent on the nature of counter-ions.

The explanation suggested by the author is that the contribution of the condensed counter-ions to the hydrodynamic friction of the polyion increases with their size.

In fact, as polyanions and positive free counter-ions move along opposed directions, electrostatic coupling gives therefore place to a process of braking rather than to a mutual entrainment. Consequently, $\lambda_{P, M}$ will rather decrease with the mobility of the counter-ions (friction effect). In contrast the condensed counter-ions are retained by the polyion and the ensemble forms a stable entity without internal frictional coupling resulting from the difference between motilities.

The present work proposes another approach in order to obtain an adequate analytical expression describing correctly the variation of the global conductibility of the MPSS polyelectrolyte with the nature and the concentration of the counter-ions. This new approach is based on a recent model in which the stretched polyion is represented by a chain of successive charged spheres, partially condensed by the counter-ions, and without introduction of specific parameters other than the structural parameters of the polyion, the valence and the effective radius of the counter-ion. Such approach will make it possible to check if the introduction of these only parameters will allow or not to explain the possible dependence of the conductibility of the polyion with nature of the counter-ions.

\section{THEORETICAL MODEL OF MANNING}

According to the Manning's conductance theory of a salt-free polyelectrolyte solution MP, the conductibility $\lambda_{P}{ }^{\text {Manning }}$ of the corresponding polyion $\mathrm{P}$ of $\mathrm{L}_{s}$ structural length and $\mathrm{Z}_{\mathrm{s}}$ e structural charge, is independent on the nature of the counter-ion $\mathrm{M}$ and varies with its total concentration $\mathrm{C}^{\circ} \mathrm{M}\left(\mathrm{mol} . \mathrm{I}^{-1}\right)$ as follows [3, 4]:

$\lambda_{P}{ }^{\text {Manning }}=-a^{\text {Manning }}\left(F e / 3 \pi \eta b_{S}\right) \operatorname{Ln}\left[X_{D} b_{S}\right]\left(1+\beta_{i r}{ }^{\text {Manning }}\right)^{-1}$

$\lambda_{P}{ }^{\text {Manning }}$ expresses the different friction effects undergone by the polyion i.e.: the hydrodynamic effect, the electrophoretic effect and the ionic relaxation effect via the viscosity $\eta$ of the solvent $\left(\eta=0.890310^{-2}\right.$ poises for water at $\left.25^{\circ} \mathrm{C}\right)$, the screen parameter $X_{D}$ and the ionic friction coefficient $\beta_{i r}{ }^{\text {Manning }} . F$ is the Faraday so that: $F e / 6 \pi=0.82$. On the other hand, $\lambda_{P}{ }^{\text {Manning }}$ is proportional to the apparent charge of the polyion and therefore to the degree of dissociation $\alpha^{\text {Manning }}$ of the counter-ions which is in this case, independent on the concentration and on the nature of the counter-ions:

$a^{\text {Manning }}=b_{S} /\left|Z_{M}\right| L_{B}$ 
$b_{S}=L_{S} /\left|Z_{S}\right|$, is the distance of separation between two successive ionizable groups, $Z_{M}$ is the valence of the counter-ion and $L_{B}=e^{2} /\left(\varepsilon_{0} k_{B} T\right)$ is the Bjerrum length, where $k_{B}$ is the Boltzmann constant and $\varepsilon_{0}$ is the permittivity of the solvent.

$\beta_{i r}{ }^{M a n n i n g}$ is the Manning ionic friction coefficient on the polyion due to the counter-ions which is also independent on the concentration and on the nature of the counter-ion [3]:

$\beta_{\mathrm{ir}}{ }^{\text {Manning }}=0.13$

The screen parameter of Debye $X_{D}$ is given by:

$X_{D}^{2}=4 \pi 10^{-27} N_{A} L_{B}\left[\alpha^{\text {Manning }} Z_{M}^{2} C^{\circ}{ }_{M}\right]$

$\mathrm{N}_{\mathrm{A}}$ is the Avogadro number. For water at $25^{\circ} \mathrm{C}: \mathrm{L}_{\mathrm{B}}=7.156 \mathrm{~A}^{\circ}$ and $\mathrm{C}^{\circ} \mathrm{M}\left(\mathrm{mol} . \mathrm{I}^{-1}\right)$ is the total concentration of counter-ions. The practical expression of $X_{D}\left(\right.$ in $A^{0^{-1}}$ ) is:

$\mathrm{X}_{\mathrm{D}}=8.710^{-2}\left(\mathrm{~b}_{\mathrm{S}} \mathrm{C}^{\circ} \mathrm{M}\right)^{1 / 2}$

Note that $X_{D}^{-1}$ measure the cylindrical mean radius of the ionic atmosphere around the polyion assumed to be an infinite thread of apparent charge: $Z_{\mathrm{ap}} \mathrm{e}=\left(a^{\text {Manning }} Z_{\mathrm{se}}\right)$. Combination of (Eq.1, Eq. 2, Eq. 3 and Eq. 5) leads to the following practical expression of $\lambda_{P}{ }^{\text {Manning }}$ (in $\mathrm{cm}^{2} \Omega^{-1}$ equiv ${ }^{-1}$ ):

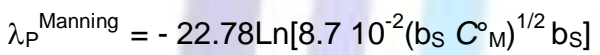

It is therefore clear that $\lambda_{P}{ }^{\text {Manning }}$ is independent of the nature of the counter-ion.

In the other hand, the expression of the ionic conductivity $\lambda_{M}$ of the counter-ions $M$ can be decomposed as follows:

$\lambda_{M}=\left(\lambda^{\circ} \mathrm{M}-\left|\Delta \lambda_{M}{ }^{\mathrm{el}}\right|\right)\left(1+\beta_{\mathrm{ir}}{ }^{\mathrm{Manning}}\right)^{-1}$

$\lambda^{\circ} \mathrm{M}$ is the ionic equivalent conductivity of the counter-ion at infinite dilution which expresses both the hydrodynamic friction due to the viscosity $\eta$ of the solvent (Stokes [14]), and the dielectric friction effect [15] caused by the polarization of solvent molecules by the charge $Z_{M}$ e of the moving counter-ion.

$\left|\Delta \lambda_{M}{ }^{\text {el }}\right|$ measures the electrophoretic effect undergone by the counter-ion. The general expression of $\left|\Delta \lambda_{M}{ }^{\text {el }}\right|$ is according to the Debye-Onsager-Fuoss theory [14] given by:

$\left|\Delta \lambda_{M}{ }^{e l}\right|=\left(\left|Z_{M}\right| F e / 6 \pi n d_{M}\right) \quad ; \quad d_{M}=R_{M}+\left(X_{D}\right)^{-1}$

$R_{M}$ is the effective radius of the counter-ion "M" and $d_{M}$ is the radius of its ionic atmosphere, and $X_{D}$ is its corresponding Debye screen parameter. The final expression is therefore:

$\left|\Delta \lambda_{M}{ }^{e l}\right|=\left(82\left|Z_{M}\right| / 0.8903\right)\left\{\left(8.710^{-2}\left(b_{S} C^{\circ}\right)^{1 / 2}\right) /\left[1+8.710^{-2}\left(b_{S} C^{\circ}{ }_{M}\right)^{1 / 2} R_{M}\right]\right\}$

Now, the Manning expression of the conductibility $\Lambda_{\mathrm{MP}}{ }^{\text {Manning }}$ of the polyelectrolyte MP is:

$\Lambda_{\mathrm{MP}}^{\text {Manning }}=\alpha^{\text {Manning }}\left[\lambda_{P}^{\text {Manning }}+\lambda_{M}\right]$

Combination of (Eq.2, Eq.3, Eq.6, Eq.7, Eq.9 and Eq.10) leads to the following practical expression of $\Lambda_{\mathrm{MP}}{ }^{\mathrm{Manning}}$ (in $\mathrm{cm}^{2} \Omega^{-}$ ${ }^{1}$ equiv $\left.^{-1}\right)$ : 
$\Lambda_{\mathrm{MP}}{ }^{\text {Manning }}=\left(\mathrm{b}_{\mathrm{S}} / 8.08\right)\left\{\lambda^{\circ}{ }_{\mathrm{M}}-25.74 \operatorname{Ln}\left[0.087\left(\mathrm{~b}_{\mathrm{S}} C^{\circ}{ }_{\mathrm{M}}\right)^{1 / 2} \mathrm{~b}_{\mathrm{S}}\right]-8.01\left(\mathrm{~b}_{\mathrm{S}} C^{\circ}{ }_{\mathrm{M}}\right)^{1 / 2} /\left[1+0.087\left(\mathrm{~b}_{\mathrm{S}} C^{\circ}{ }_{\mathrm{M}}\right)^{1 / 2} \mathrm{R}_{\mathrm{M}}\right]\right\}$

Tables $1 \mathrm{a}, 1 \mathrm{~b}$ and Figures $1 \mathrm{a}, 1 \mathrm{~b}$ give the variations with the total ionic concentration $\mathrm{C}^{\circ} \mathrm{M}$ of the Manning conductibility $\Lambda_{M P}{ }^{\text {Manning }}$ and of the experimental equivalent conductivity $\Lambda_{M P}$ of a polyelectrolyte MP, corresponding to the following polyelectrolytes (Polystyrene Sulphonates): KPSS, NaPSS, LiPSS, Et ${ }_{4} N P S S$ and $\mathrm{Bu}_{4} \mathrm{NPSS}$ in water at $25^{\circ} \mathrm{C}$. Note that the PSS polyanion is characterized by the structural parameters: $L_{S}=7250 A^{\circ}, Z_{S}=-2900$ and therefore $b_{S}=2.5 A^{\circ}$ and $a^{\text {Manning }}=0.35$. We can conclude from these comparisons that conductibilities calculated from Manning's approach are larger than the experimental equivalent conductivity $\Lambda_{\mathrm{MP}}$.

Table 1a. Variation with the counter-ion concentration $\mathrm{C}_{\mathrm{M}}{ }^{+}$of the Manning conductibilities $\Lambda_{\mathrm{MP}}{ }^{\text {Manning }}$ and the experimental equivalent conductivity $\Lambda_{\mathrm{MP}}$ of a polyelectrolyte MP, of different polyelectrolytes (Polystyrene Sulphonate MPSS): KPSS, NaPSS and LiPSS in water at $25^{\circ} \mathrm{C}$.

\begin{tabular}{|c|c|c|c|c|c|c|}
\hline $\begin{array}{c}C_{\mathrm{M}^{+}} \\
\mathrm{mol.}^{-1}\end{array}$ & $\begin{array}{c}\Lambda_{\text {KPSS }} \\
\mathrm{cm}^{2} \Omega^{-1} \text { equiving }^{-1}\end{array}$ & $\begin{array}{c}\Lambda_{\text {KPSS }} \\
\mathrm{cm}^{2} \Omega^{-1} \text { equiv }^{-1}\end{array}$ & $\begin{array}{c}\Lambda_{\text {NaPSS }}{ }^{\text {Manning }} \\
\mathrm{cm}^{2} \Omega^{-1} \text { equiv }^{-1}\end{array}$ & $\begin{array}{c}\Lambda_{\text {NaPSS }} \\
\mathrm{cm}^{2} \Omega^{-1} \text { equiv }^{-1}\end{array}$ & $\begin{array}{c}\Lambda_{\text {LiPSS }}{ }^{\text {Manning }} \\
\mathrm{cm}^{2} \Omega^{-1} \text { equiv }^{-1}\end{array}$ & $\begin{array}{c}\Lambda_{\text {LiPSS }} \\
\mathrm{cm}^{2} \Omega^{-1} \text { equiv }^{-1}\end{array}$ \\
\hline $510^{-4}$ & 61.489 & 44.585 & 54.242 & 35.734 & 50.711 & 31.879 \\
\hline $110^{-3}$ & 58.691 & 44.210 & 51.443 & 35.586 & 47.912 & 31.777 \\
\hline $1.510^{-3}$ & 57.047 & 43.921 & 49.799 & 35.462 & 46.269 & 31.675 \\
\hline $210^{-3}$ & 55.877 & 43.718 & 48.629 & 35.364 & 45.099 & 31.573 \\
\hline $2.510^{-3}$ & 54.968 & 43.601 & 47.720 & 35.290 & 44.190 & 31.471 \\
\hline $310^{-3}$ & 54.223 & 43.570 & 46.975 & 35.241 & 43.446 & 31.370 \\
\hline $3.510^{-3}$ & 53.592 & 43.624 & 46.344 & 35.2175 & 42.815 & 31.268 \\
\hline
\end{tabular}

Table 1b. Variation with the counter-ion concentration $\mathrm{C}_{\mathrm{M}}{ }^{+}$of the Manning conductibilities $\Lambda_{\mathrm{MP}}{ }^{\text {Manning }}$ and the experimental equivalent conductivity $\Lambda_{\mathrm{MP}}$ of a polyelectrolyte MP, of different Polystyrene Sulphonate MPSS: Et ${ }_{4} N P S S$ and Bu${ }_{4} N P S S$ in water at $25^{\circ} \mathrm{C}$.

\begin{tabular}{|c|c|c|c|c|}
\hline $\begin{array}{c}\mathrm{C}_{\mathrm{M}}^{\circ} \\
\mathrm{mol.}^{-1}\end{array}$ & $\begin{array}{l}\Lambda_{\text {Et4NPSS }} \text { Manning } \\
\mathrm{cm}^{2} \Omega^{-1} \text { equiv }^{-1}\end{array}$ & $\begin{array}{c}\Lambda_{\text {Et4NPSS }} \\
\mathrm{cm}^{2} \Omega^{-1} \text { equiv }^{-1}\end{array}$ & $\begin{array}{l}\Lambda_{\text {Bu4NPSS }}{ }^{\text {Manning }} \\
\mathrm{cm}^{2} \Omega^{-1} \text { equiv }^{-1}\end{array}$ & $\begin{array}{c}\Lambda_{\text {Bu4NPSS }} \\
\mathrm{cm}^{2} \Omega^{-1} \text { equiv }^{-1}\end{array}$ \\
\hline $510^{-4}$ & 48.853 & 24.942 & 44.764 & 18.100 \\
\hline $110^{-3}$ & 46.054 & 24.525 & 41.966 & 17.608 \\
\hline $1.510^{-3}$ & 44.411 & 24.187 & 40.323 & 17.202 \\
\hline $210^{-3}$ & 43.242 & 23.927 & 39.154 & 16.882 \\
\hline $2.510^{-3}$ & 42.332 & 23.746 & 38.245 & 16.646 \\
\hline $310^{-3}$ & 41.588 & 23.643 & 37.501 & 16.496 \\
\hline $3.510^{-3}$ & 40.957 & 23.618 & 36.871 & 16.432 \\
\hline
\end{tabular}




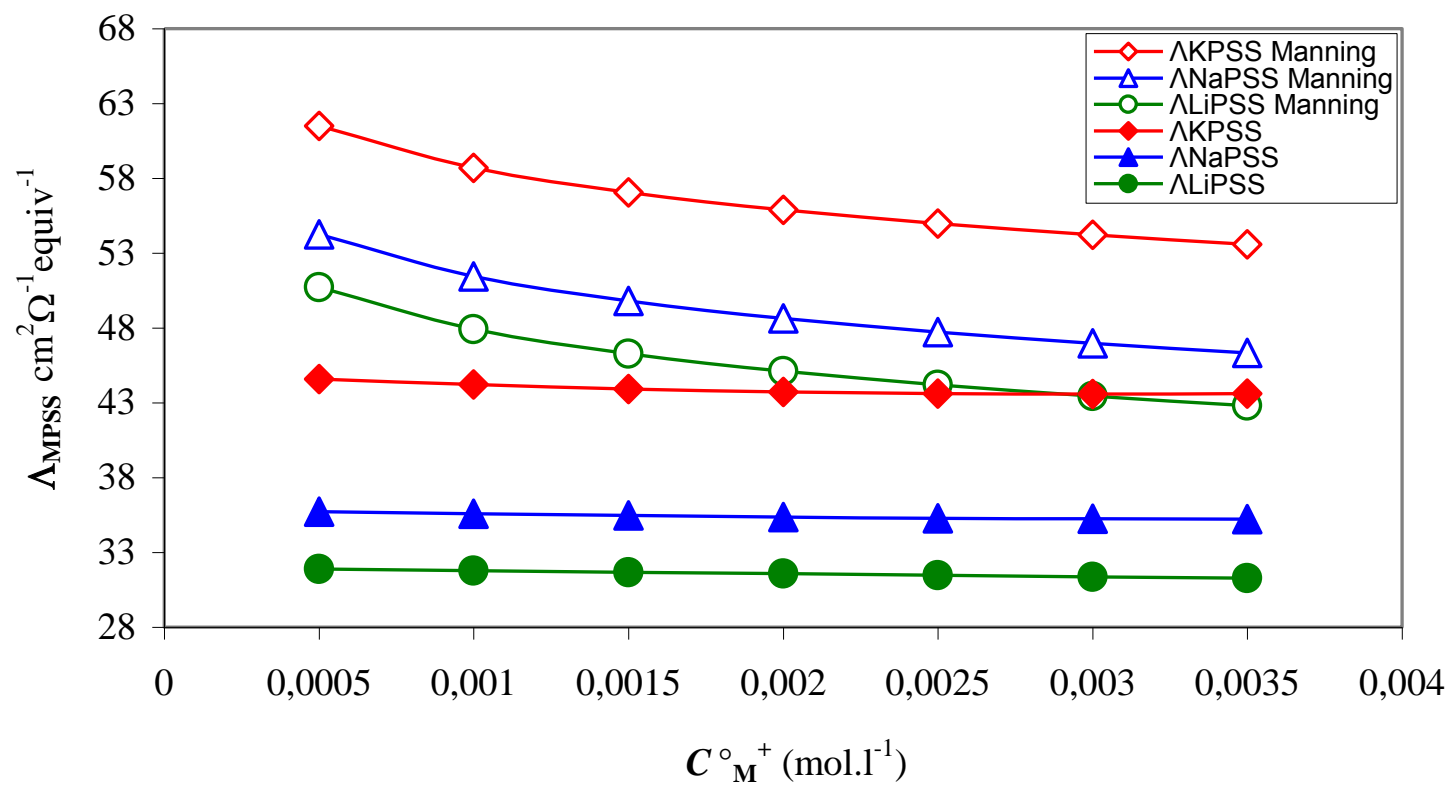

Figure 1a. Comparison for different $C^{\circ}{ }_{M}{ }^{+}$of: the Manning conductibility $\Lambda_{\text {KPSS }}{ }^{\text {Manning }}, \Lambda_{\text {NaPSS }}{ }^{\text {Manning }}, \Lambda_{\text {LiPSS }}{ }^{\text {Manning }}$, the

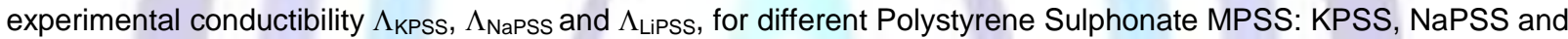
LiPSS in water at $25^{\circ} \mathrm{C}$.

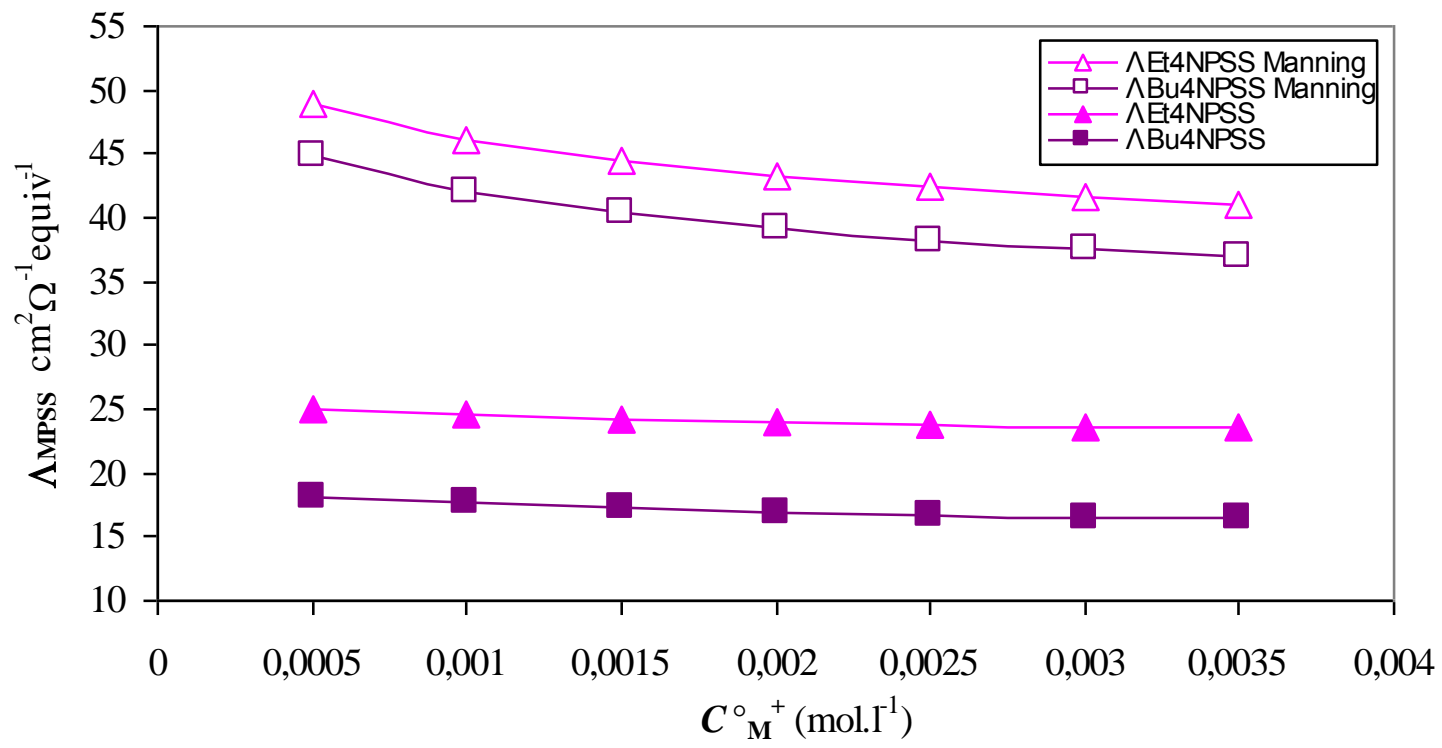

Figure 1b. Comparison for different $C^{\circ} \mathrm{M}^{+}$of: the Manning conductibility $\Lambda_{\text {Et4NPSS }}{ }^{\text {Manning }}, \Lambda_{\text {ButNPSS }}{ }^{\text {Manning }}$, the experimental conductibility $\Lambda_{\text {Et4NPSS, }} \Lambda_{\text {Bu4NPSS }}$ of Et ${ }_{4}$ NPSS and Bu${ }_{4}$ NPSS in water at $25^{\circ} \mathrm{C}$.

\section{VINK'S APPROACH}

\subsection{Principle of Experimental determination of $\alpha_{M}$ and $\lambda_{P S S, M}$}

According to Vink's approach [11-13], the experimental equivalent conductivity $\Lambda_{\mathrm{MP}}$ of a polyelectrolyte MP can be written empirically as following:

$\Lambda_{M P} \equiv \alpha_{M}\left[\lambda_{M}+\lambda_{P, M}\right] \approx\left(1-\beta_{\text {irP,M }}\right) \alpha_{M}\left[\lambda_{M}^{\prime}+\lambda_{P, M}^{\prime}\right]$ 
Eq. 12 relates $\Lambda_{M P}$ to four physical quantities: $\beta_{\text {irP.M }}, \alpha_{M}, \lambda_{M}^{\prime}$ and $\lambda_{P, M}^{\prime}$. As previously, the factor $\left(1-\beta_{\text {irP,M }}\right)$ represents the interionic friction due to the ionic relaxation effect. It is important to note that from irreversible thermodynamics considerations and for a salt-free polyelectrolyte, the friction coefficient $\beta_{\text {irP.M }}$ is the same for polyions and counter-ions $[6,11-13,16] . \alpha_{M}$ is the degree of dissociation of the polyelectrolyte which determines the effective charge $Z_{\text {ape }}$ of the polyion so that:

$Z_{a p} e=\alpha_{M} Z_{s}$

$Z_{S}$ is the stoichiometric charge number of the polyion.

Note that $\lambda_{M}^{\prime}$ and $\lambda_{P, M}^{\prime}$ are different from respectively the equivalent conductivity of the free counter-ions $\left(\lambda_{M}\right)$ and from the equivalent conductivity of the polyion $\left(\lambda_{P, M}\right)$.

All these quantities generally depend on the concentration of the polyelectrolyte and on the nature of the counter-ions. This last dependence is indicated by the index $M$. The experimental determination of $\beta_{\text {irP,M, }}, \alpha_{M}, \lambda^{\prime} M$ and $\lambda_{P, M}^{\prime}$ needs in addition to Eq.12 of three other relations.

The second relation is obtained from the net charge transported by the polyion which is measured by its electric transport number $t_{P, M}$ :

$t_{P, M}=\lambda_{P, M} /\left(\lambda_{P, M}+\lambda_{M}\right)=\lambda_{P, M}^{\prime} /\left(\lambda_{P, M}^{\prime}+\lambda_{M}^{\prime}\right)$

Where the dependence of $t_{P, M}$ with the nature of the counter-ion is indicated by the index $M$. However, in solutions with ionic association only the corresponding ionic constituent transport number $\mathrm{T}_{\mathrm{P}, \mathrm{M}}$ is experimentally determinable [12]:

$\mathrm{T}_{\mathrm{P}, \mathrm{M}}=\mathrm{t}_{\mathrm{P}, \mathrm{M}} / \mathrm{a}_{\mathrm{M}}$

Tables $2 a$ and $2 b$, give the variation of $T_{P, M}$ and $\Lambda_{M P}$ with the concentration for different types of counter-ions.

From equations (Eq.14 and Eq.15) we obtain another form of Eq.14:

$\lambda_{P, M}=T_{P, M} \Lambda_{M P}$

From Eq.16, $\lambda_{P, M}$ appears as well as a pure experimental quantity because it is related to the experimental values: $T_{P, M}$ and $\Lambda_{\mathrm{MP}}$.

The third relation is obtained by neglecting the electrophoretic friction undergone by the counter-ions $M$, for dilute solutions, so that:

$\lambda_{M}^{\prime} \approx \lambda^{\circ} \mathrm{M}$

$\lambda^{\circ} \mathrm{M}$ is equal to the ionic conductibility of $\mathrm{M}$ at infinite dilution.

According to Vink's approach, the fourth relation is obtained by assuming Manning's model for the ionic friction coefficient

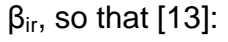

$\left(1-\beta_{\text {irP,M }}\right)=\left(1-\beta_{\text {ir }}^{\text {Manning }}\right)=0.87$

It means that $\beta_{\text {ir }}$ is independent on the nature and on the concentration of counter-ions. Logically, in turn, if Eq. 18 is valid, then also: $\alpha_{M}=\alpha^{\text {Manning }}=b_{S} /\left|Z_{M}\right|_{B}=0.35$. (Or at least $\alpha_{M} \approx$ Cste: Manning's regime [6-7, 17]). It is possible to test this assumption by calculating $\alpha_{M}$ after combination of Eqs. $(12,15,17)$ :

$\alpha_{M} \approx \Lambda_{M P} /\left[\left(1-\beta_{\text {ir }}\right) \lambda^{\circ}{ }_{M}+T_{P, M} \Lambda_{M P}\right]$ 
Table 3 gives for different types of counter-ions the variation of their corresponding $\alpha_{M}$ with the counter-ion concentration according to Eq. 19 , using $\left(1-\beta_{i r}\right)=0.87$, and the experimental values of $T_{P, M}$ and $\Lambda_{M P}$ given in tables $2 a$ and $2 b$. It shows that for all ions, $\alpha_{M}$ increases slowly with the concentration of about $3 \%$ in the concentration range between $510^{-4} M$ and $3.510^{-3} \mathrm{M}$. On the other hand, $\alpha_{M}$ values are practically the same for $\mathrm{Na}^{+}$and $\mathrm{K}^{+}$with a mean value of about 0.35 (i.e. equal to the Manning's value). However, $\mathrm{a}_{\mathrm{M}}$ values of $\mathrm{Li}^{+}$are larger of about $4.5 \%$. In contrast, $\mathrm{a}_{\mathrm{M}}$ values for organic counter-ions $\mathrm{Et}_{4} \mathrm{~N}^{+}$and $\mathrm{Bu}_{4} \mathrm{~N}^{+}$are lower (of about respectively $10 \%$ and $11.5 \%$ ). We can conclude that Manning's assumption based on electrostatic condensation seems valid for alkaline ions, but in the case of organic counter-ions, the condensation effect is enhanced by the hydrophobic attraction between polyions and organic cations.

Moreover, in order to justify his assumption expressed by Eq. 18, Vink proposed a new method based on the following equation obtained after rearranging Eq. 19:

$T_{P, M}=\left(1 / \alpha_{M}\right)-\left(1-\beta_{\text {ir }}\right)\left[\lambda^{\circ} M / \Lambda_{M P}\right]$

Indeed, if (in accordance with Manning's theory), both $\alpha_{M}$ and $\left(1-\beta_{\text {ir }}\right)$ are independent on the counter-ion species, we get (1- $\left.\beta_{\text {ir }}\right)$ as the slope of the line obtained when $T_{P, M}$ is plotted against $\left(\lambda^{\circ} \mathrm{M} / \Lambda_{M P}\right)$ (calculated for the different counter-ions; see tables $2 \mathrm{a}$ and $2 \mathrm{~b}$ ). However, calculations according to Eqs. (18 and 19), show that for a given concentration $C^{\circ}{ }^{+}$, the $\alpha_{M}$ vary slightly with the nature of the counter-ions. Therefore, we can replace $\alpha_{M}$ in Eq. (20), by its means value $<\alpha_{M}>$ given in table 3, so that:

$\left(<\alpha_{M}>^{-1}-T_{P, M}\right)=\left(1-\beta_{\text {ir }}\right)\left[\lambda^{\circ} M / \Lambda_{M P}\right]$

Note that this method is valid even if $\left\langle\alpha_{M}>\right.$ depends on the counter-ion concentration.

Tables $2 \mathrm{a}$ and $2 \mathrm{~b}$ give the experimental variations with the counter-ion concentration $C^{\circ}{ }^{+}$of $\Lambda_{M P}, T_{P, M}$ and $\left(\lambda^{\circ}{ }_{M} \Lambda_{M P}\right)$ in the case of different polyelectrolytes (Polystyrene Sulphonate MPSS: KPSS, NaPSS, LiPSS, Et ${ }_{4} N P S S$ and Bu ${ }_{4} N P S S$ ), in water at $25^{\circ} \mathrm{C}$. All these data allow the calculation for each polyelectrolyte and for different concentrations $\left(C^{\circ}{ }^{+}=110^{-3} \mathrm{M}\right.$, $\left.210^{-3} \mathrm{M}, 310^{-3} \mathrm{M}\right)$, of its corresponding dissociation coefficient $\alpha_{\mathrm{M}}$. On the other hand, figure 2 shows that for the three concentrations $\left(C_{M}^{\circ}{ }^{+}=110^{-3} \mathrm{M}, 210^{-3} \mathrm{M}, 310^{-3} \mathrm{M}\right.$, with respectively: $<\mathrm{a}_{\mathrm{M}}>=0.328,0.342$ and 0.35$)$, the three curves giving the variation of $\left(\left\langle\alpha_{M}>^{-1}-T_{P, M}\right)\right.$ with $\left(\lambda^{\circ} M / \Lambda_{M P}\right)$, are practically superimposed on only one line passing by the origin, and having a slope $\left(1-\beta_{\text {ir }}\right)$, practically independent on the concentration with a mean value of about $(0.87)$ i.e. equal to that predicted by Eq. 18 and by Manning's theory.

Table 2a. Variation with the counter-ion concentration $C^{\circ}{ }^{+}$of: the experimental conductibility $\Lambda_{\mathrm{MPSS}}$, the experimental transport number $T_{P, M}{ }^{M P S S}$ and $\left(\lambda^{\circ}{ }_{M} / \Lambda_{M P S S}\right)$ of different Polystyrene Sulphonate MPSS: KPSS, NaPSS and LiPSS in water at $25^{\circ} \mathrm{C}$.

\begin{tabular}{|c|c|c|c|c|c|c|c|c|c|}
\hline $\begin{array}{c}\mathrm{C}_{\mathrm{M}}^{+} \\
\mathrm{mol} . \mathrm{I}^{-1}\end{array}$ & $\begin{array}{c}\Lambda_{\text {KPSS }} \\
\mathrm{cm}^{2} \Omega_{1}^{-1} \text { equiv }\end{array}$ & $\mathrm{T}_{\mathrm{P}, \mathrm{M}}{ }^{\mathrm{KPSS}}$ & $\begin{array}{c}\lambda^{\circ} \mathrm{K}^{+} / \Lambda_{\mathrm{KPSS}} \\
\left(\lambda^{\circ} \mathrm{K}^{+}=73.5\right)\end{array}$ & $\begin{array}{c}\Lambda_{\mathrm{NaPSS}} \\
\mathrm{cm}^{2} \Omega_{1}^{-1} \text { equiv }\end{array}$ & $\mathrm{T}_{\mathrm{P}, \mathrm{M}}{ }^{\mathrm{NaPSS}}$ & $\begin{array}{c}\lambda^{\circ} \mathrm{Na}^{+} / \Lambda_{\mathrm{NaPSS}} \\
\left(\lambda^{\circ} \mathrm{Na}^{+}=\right. \\
50.1)\end{array}$ & $\begin{array}{c}\Lambda_{\text {LiPSS }} \\
\mathrm{cm}^{2} \Omega_{1}^{-1} \text { equiv }\end{array}$ & $\mathrm{T}_{\mathrm{P}, \mathrm{M}}{ }^{\text {LiPSS }}$ & $\begin{array}{l}\lambda_{\mathrm{Li}}^{\circ} / \Lambda_{\mathrm{LiPSS}} \\
\left(\lambda^{\circ} \mathrm{Li}^{+}=38.7\right)\end{array}$ \\
\hline $110^{-3}$ & 44.210 & 1.439 & 1.6625 & 35.586 & 1.772 & 1.4078 & 31.777 & 1.805 & 1.2178 \\
\hline $1.510^{-3}$ & 43.921 & 1.399 & 1.6734 & 35.462 & 1.679 & 1.4127 & 31.675 & 1.714 & 1.2219 \\
\hline $2.510^{-3}$ & 43.601 & 1.325 & 1.6857 & 35.290 & 1.554 & 1.4196 & 31.471 & 1.588 & 1.2297 \\
\hline $310^{-3}$ & 43.570 & 1.291 & 1.6870 & 35.241 & 1.522 & 1.4216 & 31.370 & 1.552 & 1.2336 \\
\hline $3.510^{-3}$ & 43.624 & 1.260 & 1.6848 & 35.2175 & 1.510 & 1.4225 & 31.268 & 1.536 & 1.2377 \\
\hline
\end{tabular}


Table 2b. Variation with the counter-ion concentration $\mathrm{C}^{\circ}{ }_{\mathrm{M}}^{+}$of: the experimental conductibility $\Lambda_{\mathrm{MPSS}}$, the experimental transport number $\mathrm{T}_{\mathrm{P}, \mathrm{M}}{ }^{\mathrm{MPSS}}$ and $\left(\lambda^{\circ}{ }_{\mathrm{M}} / \Lambda_{\mathrm{MPSS}}\right)$ of Et ${ }_{4} \mathrm{NPSS}$ and $\mathrm{Bu}_{4} \mathrm{NPSS}$ in water at $25^{\circ} \mathrm{C}$.

\begin{tabular}{|c|c|c|c|c|c|c|}
\hline$C^{\circ}{ }^{+}$mol. $^{-1}$ & $\begin{array}{c}\Lambda_{\text {Et4NPSS }} \\
\mathrm{Cm}^{2} \Omega_{1}^{-1} \text { equiv }\end{array}$ & $T_{\mathrm{P}, \mathrm{M}}{ }^{\text {Et4NPSS }}$ & $\begin{array}{c}\lambda^{\circ}{ }_{\text {Et4N }}^{+} / \Lambda_{\text {Et4NPSS }} \\
\left(\lambda^{\circ}{ }_{\text {Et4N }}^{+}=32.7\right)\end{array}$ & $\begin{array}{c}\Lambda_{\text {Bu4NPSS }} \\
\mathrm{cm}^{2} \Omega_{1}^{-1} \text { equiv }\end{array}$ & $T_{\mathrm{P}, \mathrm{M}^{\text {Bu4NPS }}}$ & $\begin{array}{c}\lambda^{\circ}{ }_{\text {Bu4N }} / \Lambda_{\text {Bu4NPSS }} \\
\left(\lambda^{\circ} \text { Et4N }^{+}=19.5\right)\end{array}$ \\
\hline $510^{-4}$ & 24.942 & 2.122 & 1.3110 & 18.100 & 2.513 & 1.0773 \\
\hline $110^{-3}$ & 24.525 & 2.056 & 1.3333 & 17.608 & 2.373 & 1.1073 \\
\hline $1.510^{-3}$ & 24.187 & 1.996 & 1.3520 & 17.202 & 2.264 & 1.1337 \\
\hline $210^{-3}$ & 23.927 & 1.942 & 1.3666 & 16.882 & 2.187 & 1.1552 \\
\hline $2.510^{-3}$ & 23.746 & 1.895 & 1.3771 & 16.646 & 2.141 & 1.1712 \\
\hline $310^{-3}$ & 23.643 & 1.854 & 1.3831 & 16.496 & 2.125 & 1.1818 \\
\hline $3.510^{-3}$ & 23.618 & 1.819 & 1.3845 & 16.432 & 2.141 & 1.1868 \\
\hline
\end{tabular}

Table 3. Variation with the counter-ion concentration $\mathrm{C}_{\mathrm{M}}{ }^{+}$of the degree of dissociation $\mathrm{a}_{\mathrm{M}}$ of different Polystyrene Sulphonate MPSS: KPSS, NaPSS, LiPSS, Et ${ }_{4}$ NPSS and $\mathrm{Bu}_{4}$ NPSS in water at $25^{\circ} \mathrm{C} .\left(<\alpha_{M}>\right.$ is the average degree of dissociation for each concentration).

\begin{tabular}{|c|c|c|c|c|c|c|}
\hline $\mathrm{C}^{\circ}{ }^{+} \mathrm{mol}^{-I^{-1}}$ & $\alpha_{\mathrm{K}}$ & $\alpha_{\mathrm{Na}}$ & $\alpha_{\mathrm{Li}}$ & $\alpha_{\mathrm{Et} 4 \mathrm{~N}}$ & $\alpha_{\mathrm{Bu} 4 \mathrm{~N}}$ & $<\alpha_{\mathrm{M}}>$ \\
\hline $510^{-4}$ & 0.343 & 0.322 & 0.336 & 0.306 & 0.290 & 0.319 \\
\hline $110^{-3}$ & 0.346 & 0.334 & 0.349 & 0.311 & 0.299 & 0.328 \\
\hline $1.510^{-3}$ & 0.350 & 0.344 & 0.360 & 0.315 & 0.307 & 0.335 \\
\hline $210^{-3}$ & 0.354 & 0.353 & 0.369 & 0.319 & 0.313 & 0.342 \\
\hline $2.510^{-3}$ & 0.358 & 0.358 & 0.376 & 0.323 & 0.316 & 0.346 \\
\hline $310^{-3}$ & 0.362 & 0.362 & 0.381 & 0.327 & 0.317 & 0.350 \\
\hline $3.510^{-3}$ & 0.367 & 0.364 & 0.383 & 0.331 & 0.315 & 0.352 \\
\hline
\end{tabular}

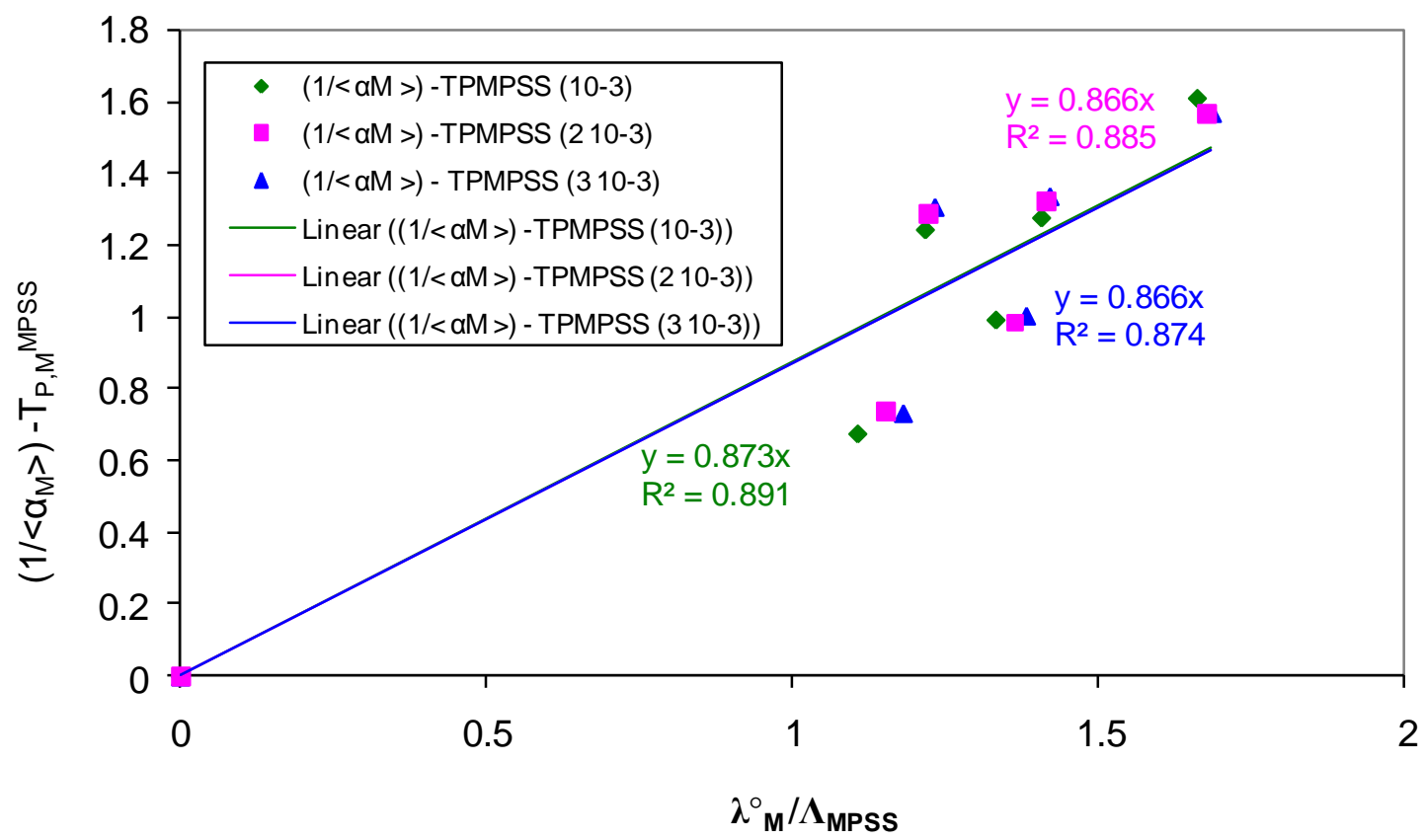

Figure 2. Variations of $\left.y=\left(<\alpha_{M}\right\rangle^{-1}-T_{P, M}\right)$ with $\left(\lambda^{\circ} M / \Lambda_{M P}\right)$ with $x=\left(\lambda^{\circ}{ }_{M} / \Lambda_{M P S S}\right)$, for three concentrations: $110^{-3} M$, 2 $10^{-3} \mathrm{M}$ and $310^{-3} \mathrm{M}$, for different Polystyrene Sulphonate MPSS: KPSS, NaPSS, LiPSS, Et ${ }_{4} N P S S$ and Bu ${ }_{4} N P S S$ in water at $25^{\circ} \mathrm{C}$. 
However, despite the apparent compatibility of the Vink's approach with the Manning's model, at least concerning the quasi-stability of the values $\alpha_{M}$ and (1- $\left.\beta_{i r}\right)$, direct calculation according to Eq.16, of the "experimental" values of the conductibility $\lambda_{P S S, M}$ of the PSS polyion partially condensed by the counter-ions $M$, shows a significant dependence of $\lambda_{P S S, M}$ with the nature of the counter-ion $\mathrm{M}$ (see table $4 \mathrm{a}$ ). This result is quantitatively and qualitatively in contradiction with the Manning's theory. Indeed, the values of $\lambda_{P}{ }^{\text {Manning }}$, calculated according to Manning's equation (Eq. 6), are greater than their corresponding "experimental" values: $\lambda_{P S S, M}$ of about $60 \%$. On the other hand $\lambda_{P}{ }^{\text {Manning }}$ is independent on the nature of the counter-ions M. Table $4 \mathrm{a}$ and figure $3 \mathrm{a}$, summarize all the results in the case of KPSS, NaPSS, LiPSS, Et ${ }_{4}$ NPSS and $\mathrm{Bu}_{4} \mathrm{NPSS}$ in water at $25^{\circ} \mathrm{C}$.

Table 4a. Variation with the counter-ion concentration $\mathrm{C}_{\mathrm{M}}{ }^{+}$of: the experimental conductibility $\lambda_{\mathrm{PSS}, \mathrm{M}}$, the Manning conductibility $\lambda_{P}{ }^{\text {Manning }}$, for different Polystyrene Sulphonate MPSS: KPSS, NaPSS, LiPSS, Et ${ }_{4} N P S S$ and Bu ${ }_{4} N P S S$ in water at $25^{\circ} \mathrm{C}$.

\begin{tabular}{|c|c|c|c|c|c|c|}
\hline $\mathrm{C}^{\circ}{ }^{+}{ }_{1}^{+} \mathrm{mol}^{-\mathrm{I}^{-}}$ & $\begin{array}{c}\lambda_{\mathrm{PSS}, \mathrm{K}} \\
\mathrm{cm}^{2} \Omega_{1}^{-1} \text { equiv }\end{array}$ & $\begin{array}{c}\lambda_{\mathrm{PSS}, \mathrm{Na}} \\
\mathrm{cm}^{2} \Omega^{-1} \text { equiv }^{-1}\end{array}$ & $\begin{array}{c}\lambda_{\mathrm{PSS}, \mathrm{Li}} \\
\mathrm{cm}^{2} \Omega_{1}^{-1} \text { equiv }\end{array}$ & $\begin{array}{c}\lambda_{\mathrm{PSS}, \mathrm{Et} 4 \mathrm{~N}} \\
\mathrm{~cm}^{2} \Omega_{1}^{-1} \text { equiv }\end{array}$ & $\begin{array}{c}\lambda_{\mathrm{PSS}, \mathrm{Bu} 4 \mathrm{~N}} \\
\mathrm{~cm}^{2} \Omega_{1}^{-1} \text { equiv }\end{array}$ & $\begin{array}{c}\lambda_{P}^{\text {Manning }} \\
\mathrm{cm}^{2} \Omega_{1}^{-1} \text { equiv }\end{array}$ \\
\hline $510^{-4}$ & 66.075 & 67.358 & 61.016 & 52.926 & 45.485 & 110.889 \\
\hline $110^{-3}$ & 63.618 & 63.058 & 57.357 & 50.423 & 41.783 & 102.995 \\
\hline $1.510^{-3}$ & 61.445 & 59.541 & 54.291 & 48.277 & 38.945 & 98.377 \\
\hline $210^{-3}$ & 59.500 & 56.794 & 51.811 & 46.466 & 36.921 & 95.100 \\
\hline $2.510^{-3}$ & 57.771 & 54.840 & 49.975 & 44.998 & 35.639 & 92.558 \\
\hline $310^{-3}$ & 56.248 & 53.636 & 48.686 & 43.834 & 35.054 & 90.482 \\
\hline $3.510^{-3}$ & 54.966 & 53.178 & 48.027 & 42.961 & 35.180 & 88.726 \\
\hline
\end{tabular}

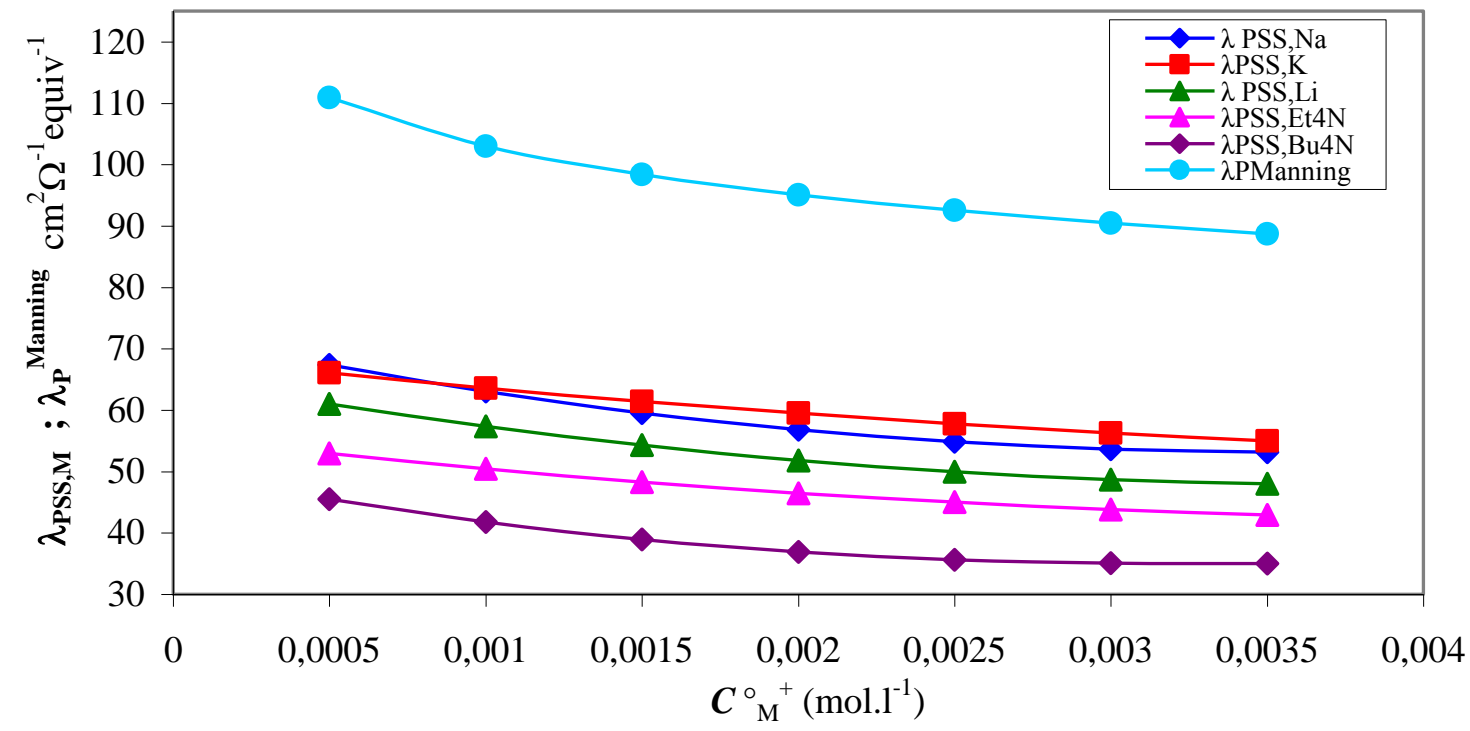

Figure 3a. Comparison between variations with the counter-ion concentration $\mathrm{C}^{\circ} \mathrm{M}^{+}$of: the experimental conductibility $\lambda_{\text {KPSS, }}$

$\lambda_{\text {NaPSS }}, \lambda_{\text {LiPSS }}, \lambda_{\text {Et4NPSS }}$ and $\lambda_{\text {Bu4NPSS }}$, the Manning conductibility $\lambda_{P}{ }^{\text {Manning }}$, for different Polystyrene Sulphonate MPSS: KPSS, NaPSS, LiPSS, Et $t_{4}$ NPSS and $\mathrm{Bu}_{4}$ NPSS in water at $25^{\circ} \mathrm{C}$.

Moreover, according to the previous Vink's approach, and with the assumption that both $\left\langle\alpha_{M}>\right.$ and (1- $\beta_{\text {ir }}$ ) are independent on the counter-ion species, combination of Eqs. 16 and 20 lead to following expression of the calculated conductibility $\lambda_{P, M}^{C}$ of the PSS polyion in terms of these two parameters: 
$\lambda_{P, M}^{C}=\left(1-\beta_{i r}\right) \lambda_{P, M}^{\prime}=\left[\Lambda_{M P} /<\alpha_{M}>\right]-\lambda^{\circ} M\left(1-\beta_{\text {ir }}\right)$

(22)

Table $4 \mathrm{~b}$ and figure $3 \mathrm{~b}$, summarize all the results in the case of KPSS, NaPSS, LiPSS, Et ${ }_{4}$ NPSS and Bu $\mathrm{HPSS}_{4}$ in water at $25^{\circ} \mathrm{C}$. Note that if Vink's approach is exact, the different $\lambda_{P, M}^{C}$ must be identical to their corresponding experimental values $\lambda_{\text {PSS,M }}$ given in table $4 \mathrm{a}$. However, we note a non- negligible dispersion of the results.

Table 4b. Variation with the counter-ion concentration $\mathrm{C}_{\mathrm{M}}{ }^{+}$of: the calculated equivalent conductivities $\lambda_{\mathrm{PSS}, \mathrm{M}}^{\mathrm{C}}$, the Manning conductibility $\lambda_{\mathrm{P}}{ }^{\text {Manning }}$ and the average degree of dissociation $\left\langle\alpha_{M}\right\rangle$, for different Polystyrene Sulphonate MPSS: KPSS, NaPSS, LiPSS, Et ${ }_{4} N P S S$ and Bu ${ }_{4} N P S S$ in water at $25^{\circ} \mathrm{C}$.

\begin{tabular}{|c|c|c|c|c|c|c|c|}
\hline $\mathrm{C}^{\circ}{ }^{+} \mathrm{mol}^{-\mathrm{I}^{-1}}$ & $<\alpha_{M}>$ & $\begin{array}{c}\lambda_{\text {PSS }, \mathrm{K}}^{\mathrm{C}} \\
\mathrm{cm}^{2} \Omega^{-1} \text { equiv }^{-1}\end{array}$ & $\begin{array}{c}\lambda_{\mathrm{PSS}, \mathrm{Na}}^{\mathrm{C}} \\
\mathrm{cm}^{2} \Omega_{1}^{-1} \text { equiv }\end{array}$ & $\begin{array}{c}\lambda_{\text {PSS,Li }}^{\mathrm{C}} \\
\mathrm{cm}^{2} \Omega_{1}^{-1} \text { equiv }\end{array}$ & $\begin{array}{c}\lambda_{\text {PSS,Et4N }}^{\mathrm{C}} \\
\mathrm{cm}^{2} \Omega_{1}^{-1} \text { equiv }\end{array}$ & $\begin{array}{c}\lambda_{\mathrm{PSS}, \mathrm{Bu} 4 \mathrm{~N}}^{\mathrm{C}} \\
\mathrm{cm}^{2} \Omega_{1}^{-1} \text { equiv }\end{array}$ & $\begin{array}{c}\lambda_{\mathrm{P}}^{\text {Manning }} \\
\mathrm{cm}^{2} \Omega_{1}^{-1} \text { equiv }\end{array}$ \\
\hline $510^{-4}$ & 0.319 & 75.819 & 68.431 & 66.265 & 49.739 & 39.774 & 110.889 \\
\hline $110^{-3}$ & 0.328 & 70.841 & 64.906 & 63.212 & 46.322 & 36.717 & 102.995 \\
\hline $1.510^{-3}$ & 0.335 & 67.162 & 62.269 & 60.883 & 43.751 & 34.384 & 98.377 \\
\hline $210^{-3}$ & 0.342 & 63.885 & 59.816 & 58.649 & 41.512 & 32.397 & 95.100 \\
\hline $2.510^{-3}$ & 0.346 & 62.069 & 58.407 & 57.287 & 40.181 & 31.144 & 92.558 \\
\hline $310^{-3}$ & 0.350 & 60.540 & 57.101 & 55.959 & 39.102 & 30.166 & 90.482 \\
\hline $3.510^{-3}$ & 0.352 & 59.986 & 56.462 & 55.160 & 38.647 & 29.716 & 88.726 \\
\hline
\end{tabular}

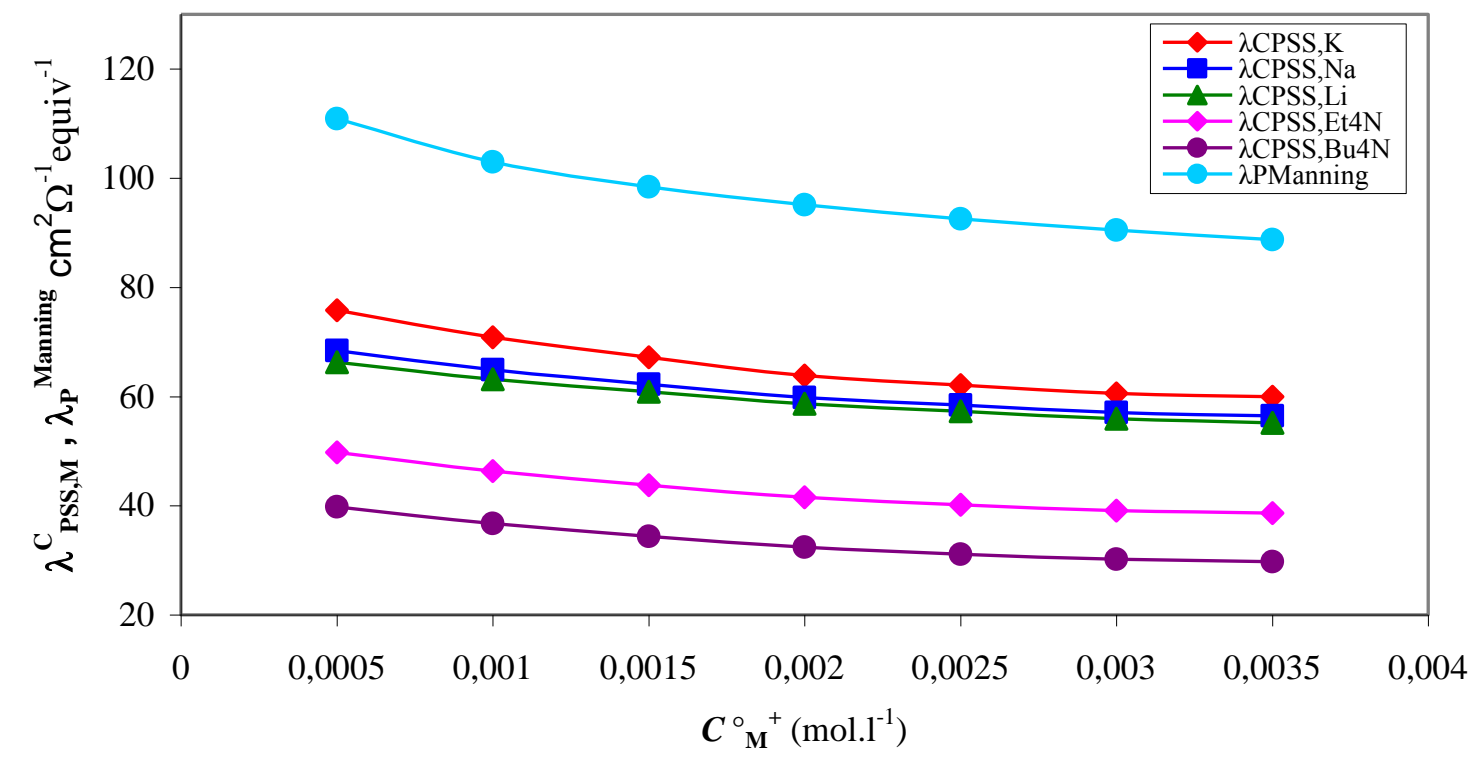

Figure 3b. Comparison between variations with the counter-ion concentration $C^{\circ}{ }^{+}$of: the calculated equivalent conductivities $\lambda^{C}$ KPSS, $\lambda^{C}$ NaPSS, $\lambda^{C}$ LiPSS, $\lambda^{C}{ }_{\text {Et4NPSS }}$ and $\lambda^{C}{ }_{\text {ButNPSS }}$, the Manning conductibility $\lambda_{P}{ }^{\text {Manning }}$, for different Polystyrene Sulphonate MPSS: KPSS, NaPSS, LiPSS, Et ${ }_{4}$ NPSS and Bu 4 NPSS in water at $25^{\circ} \mathrm{C}$.

\subsection{Vink's interpretation of the dependence of the experimental $\lambda_{P S S, M}$ with the nature of the counter-ions.}

As indicated previously, the Manning's model is not able to explain the dependence of the polyion conductibility with the nature of the counter-ions $\mathrm{M}$ because the polyion is assumed to be an infinite thread and the counter-ions are modeled as punctual charges. In contrast, Vink suggests a more realistic description which offers an explanation of the dependence of the conductibility of the polyion with the size $\mathrm{R}_{\mathrm{M}}$ of the condensed counter-ions species. Indeed, according to his model, 
the hydrodynamic friction on the polyion increases with the minimal distance of approach $\left(R_{C, M}=R_{C}+R_{M}+n R_{w}\right)$ between a condensed counter-ion and a charged polyion group. $R_{C}$ is the radius of the polyion, $R_{w}$ is the radius of water molecule and $n R_{w}$ is a correction due to the hydration effect with: $n=0,1$ or 2 .

In the following section we will demonstrate that this interpretation is correct in its principle but it cannot explain the important decrease of $\lambda_{\text {PSS }, M}$ with the size $\mathrm{R}_{\mathrm{M}}$ of the condensed counter-ions species (from $\mathrm{K}^{+}$to $\mathrm{Bu}_{4} \mathrm{~N}^{+}$) which is of about $35 \%$.

\section{MODELING OF POLYION AS STRETCHED CHAIN OF CHARGED SPHERES}

\subsection{Conductivity of Stretched Polyelectrolyte in Dilute Solutions}

The expression of the equivalent conductivity $\lambda_{\mathrm{P}, \mathrm{M}}$ of a polyion is in fact more complex because its ionic equivalent conductivity at infinite dilution $\lambda_{P}{ }^{\circ}$ expresses both hydrodynamic friction effect via $\lambda_{P}{ }^{\circ \text { Hyd }}$ and dielectric friction effect via $\beta_{\mathrm{P}}{ }^{\mathrm{dfi}}[6]$. For this reason, we can decompose $\lambda_{\mathrm{P}, \mathrm{M}}$ as follows:

$\lambda_{P, M}=\left(\alpha_{C M} \lambda_{P}{ }^{\text {Hyd }}-\Delta \lambda_{P}{ }^{e l}\right) /\left(1+\beta_{i r}{ }^{P}+\beta_{P}{ }^{\text {dfi }}\right)=\lambda_{P}{ }^{\text {Henry }} /\left(1+\beta_{i r}{ }^{P}+\beta_{P}{ }^{d f i}\right)$

$\alpha_{\mathrm{CM}}$ is the degree of dissociation of the polyelectrolyte for which the polyion is modeled as a chain of charged spheres. $\lambda_{P}{ }^{\circ H y d}$ is the purely hydrodynamic contribution due to the viscosity $\eta$ of the solvent, and $\Delta \lambda_{P}{ }^{\text {el }}$ is the so-called electrophoretic effect which expresses the hydrodynamic friction on the ionic atmosphere of the polyion. $\beta_{\mathrm{ir}}{ }^{\mathrm{P}}$ is the ionic friction coefficient of the polyion.

\subsubsection{Hydrodynamic friction and Electrophoretic effect}

In previous works $[6-8,16,17]$, we have noted that the first term $\left(\alpha_{C M} \lambda_{P}{ }^{\circ H y d}-\Delta \lambda_{P}{ }^{\text {el }}\right)$ is identical to the expression of the Henry equivalent conductivity $\lambda_{P}{ }^{\text {Henry }}$ given by $[6,18]$ :

$\lambda_{P}{ }^{\text {Henry }}=\alpha_{C M}\left|Z_{S}\right| F e / 6 \pi \eta C_{A P}^{\prime}$

$F$ is the Faraday, e is the proton charge and $C^{\prime}{ }_{A P}$ is in fact the electrostatic Gouy capacitance (in c.g.s.u.e units) of the ellipsoidal (or cylindrical) capacitor constituted by the polyion and by its ionic atmosphere of mean radius $\left\langle\mathrm{d}_{\mathrm{p}}\right\rangle$. Eq. 24 is a generalization of the Stokes-Hubbard equation [19].

$\left(C^{\prime}{ }_{A P}\right)^{-1}=\left[<R_{P}>^{-1}-<d_{P}>^{-1}\right] ;<d_{P}>=L_{S} / \operatorname{Ln}\left[g\left(d_{P}, L_{S}\right)\right] ;<R_{P}>=L_{S} / \operatorname{Ln}\left[g\left(R_{C}, L_{S}\right)\right]$

$<R_{P}>$ is the mean radius of the polyion (analog to the radius of gyration) which is also equal to the electrostatic capacitance $\mathrm{C}_{\mathrm{AP}}$ (in c.g.s.u.e units) of the ellipsoidal (or cylindrical) polyion [18, 19].

$g(x, L s)=\left[\left(4 x^{2}+L_{s}^{2}\right)^{1 / 2}+L_{s}\right] /\left[\left(4 x^{2}+L_{s}^{2}\right)^{1 / 2}-L_{s}\right]$

$d_{P}=R_{C}+1 / 2 \Gamma P M S A$

$g\left(x, L_{S}\right)$ is "the configuration function" which depends on the conformation of the polyion. The thickness $d_{p}$ is of the ionic atmosphere is a function of the radius $R_{C}$ of the cylindrical chain and of $\alpha_{C M}$ and $C^{\circ}$ M via the Debye-MSA screen parameter $\Gamma_{\mathrm{PMSA}}[20]$ and the Debye length $\mathrm{XD}^{-1}$.

$2 \Gamma_{\mathrm{PMSA}}=\left[-1+\left(1+4 \mathrm{X}_{\mathrm{D}} \mathrm{R}_{\mathrm{M}}\right)^{1 / 2}\right] / 2 \mathrm{R}_{\mathrm{M}} \quad ; \quad \mathrm{X}_{\mathrm{D}}^{2}=4 \pi 10^{-27} \mathrm{~N}_{\mathrm{A}} \mathrm{L}_{\mathrm{B}}\left(\mathrm{Z}_{\mathrm{M}}^{2} \mathrm{\alpha}_{\mathrm{CM}} C_{\mathrm{M}}^{\circ}\right)$

$Z_{M}$ is the valence of the counter-ion, $R_{M}$ is the effective radius of the solvated counter-ion "M", $N_{A}$ is the Avogadro number and $L_{B}$ is the Bjerrum length. 


\subsubsection{Ionic friction on the polyion}

Recall that in addition to the electrophoretic effect, one must take into account the ionic relaxation effect due to the polarization of the ionic atmosphere of the moving polyion by the external field. This local polarization induces a reacting relaxation field in order to moderate the perturbation caused by the external field. The result is a decrease of the mobility of the polyion when the concentration of the counter-ions increases via the ionic friction coefficient $\beta_{\mathrm{ir}}{ }^{\mathrm{P}}$ as indicated in Eq. 23. The expression of $\beta_{\mathrm{ir}}{ }^{\mathrm{P}}$ is given by [6-8]:

$\beta_{\text {ir }}{ }^{P}=\alpha_{C M}\left|Z_{s} Z_{M}\right| L_{B}\left(3 d_{P}^{2}+L_{s}^{2} / 4\right) /\left[18\left(d_{P}^{2}+L_{s}^{2} / 4\right)^{3 / 2}\right]$

Note that for a free salt polyelectrolyte, the ionic friction coefficient $\beta_{\mathrm{ir}}{ }^{\mathrm{P}}$ of the polyion is equal to the ionic friction coefficient $\beta_{\text {ir }}{ }^{M}$ of the counter-ions [6, 13]:

$\beta_{i r}{ }^{P}=\beta_{i r}{ }^{M}$

Note also that for spherical configuration: $L_{S} / d_{P} \rightarrow 0$, then: $\beta_{i r}{ }^{P} \rightarrow \alpha_{C M}\left|Z_{M} Z_{S}\right| L_{B} /\left(6 d_{P}\right)$, this limiting expression converges toward the Debye-Onsager relation applicable for spherical ions. In contrast, for polyions of very large length: $L_{S}>>d_{p}$ and thus: $\beta_{\mathrm{ir}}{ }^{\mathrm{P}} \rightarrow 1 / 9 \forall C^{\circ}{ }_{\mathrm{M}}$ if $\alpha_{\mathrm{CM}} \rightarrow \alpha^{\text {Manning }}$. Consequently, $\left(1-\beta_{\mathrm{ir}}{ }^{\mathrm{P}}\right) \rightarrow 0.889$, this limit is in conformity with both Manning and Vink approaches.

\subsubsection{Importance of the Dielectric Friction Effect}

In this paragraph we will discuss succinctly the dielectric frictional effect on a slowly moving polyion due to dielectric loss in its surrounding medium. Calculations of the dielectric frictional force on a charged sphere were performed successively by R. Zwanzig [15], J. Hubbard and L. Onsager [23] and P. G. Wolynes [21]. However, this dielectric effect is completely ignored by the Manning's model and it is not cited in the Vink's approach.

Indeed, the apparent charge $\left(\alpha_{\mathrm{cm}} Z_{s} e\right)$ of a polyion moving along $\mathrm{Oz}$ with a velocity $\mathrm{v}$, induces a polarization of its surrounding dielectric medium which in turn creates after a relaxation time $\mathrm{T}$ (delay) a dielectric frictional force $\mathrm{F}_{\mathrm{z}}$ acting on the polyion. In fact, this force depends on the conformation (shape) of the polyion [6-8, 16-18]. In the case of a coiled polyion represented by an ellipsoidal conformation, the expression of $F_{z}$ is [18]:

$F_{Z}=-(2 / 3)(v T)\left(\varepsilon_{0}-\varepsilon_{\infty}\right) \varepsilon_{0}^{-2}\left(\alpha_{C M} Z_{s} e\right)^{2}\left(R_{a p p}\right)^{-3}=-\xi^{D} v$

The sign "-" expresses the fact that the direction of the frictional force is opposite to the direction of v. The factor (vT) expresses the delay effect so that $F_{z}$ vanishes for immobile polyion: $v=0$, or in the case of instantaneous response: $\mathrm{T}=0$. $\varepsilon_{0}$ and $\varepsilon_{\infty}$ are the static and high-frequency dielectric constants of the solvent and the $\left(\varepsilon_{0}-\varepsilon_{\infty}\right) \varepsilon_{0}{ }^{-2}$ term expresses the dielectric saturation effect. $R_{\text {app }}$ is the apparent radius of the polyion which depends on its eccentricity [18], and $\xi^{\mathrm{D}}$ is the translational dielectric friction related to the $\beta_{P}{ }^{\text {dfi }}$ coefficient via the Henry mobility $u_{P}^{\text {Henry }}=\lambda_{P}{ }^{\text {Henry }} / F$, according to [18]:

$\beta_{\mathrm{P}}{ }^{\mathrm{dfi}}=\left|\alpha_{\mathrm{CM}} Z_{S} \mathrm{e}^{-1} \xi^{\mathrm{D}} \mathrm{UP}_{\mathrm{P}}^{\text {Henry }}=(2 / 3)\left(\mathrm{uP}_{\mathrm{P}}^{\text {Henry }} \mathrm{T}\right)\left(\varepsilon_{0}-\varepsilon_{\infty}\right) \varepsilon_{\mathrm{o}}{ }^{-2}\right| \alpha_{\mathrm{CM}} Z_{\mathrm{S}} \mathrm{el}\left(\mathrm{R}_{\mathrm{app}}\right)^{-3}$

For coiled polyions, $\beta_{P}{ }^{d f i}<<1$, because of the term $\left(R_{a p p}\right)^{-3}$, and therefore according Eq. 23 , the dielectric friction effect remains weak. It is interesting to note that when the moving polyion is assumed to be a thread of infinite length $(L \rightarrow \infty)$ with a continuous linear charge (Manning's Model), so that the local distribution of its surrounding solvent molecules remains undisturbed, the polyion appears therefore as an equivalent immobile polyion (no dielectric friction).

In the specific case of a stretched polyion modeled as a chain of $\left|Z_{S}\right|$ identical spheres of charge $q_{n}=a_{c m e}$ and of radius $\mathrm{R}_{\mathrm{g}, \mathrm{M}}$ (a linear discontinuous distribution of ionized groups), each partially charged group undergone a dielectric friction effect proportional to $\left(R_{g, M}\right)^{-3}$ and not to $\left(R_{a p p}\right)^{-3}$ (with $R_{g, M}<<R_{a p p}$ ) and consequently, the conformation transition from coiled state to stretched state will be accompanied by a sharp increase of the dielectric friction on the polyion. The corresponding expression of the dielectric friction coefficient $\beta_{P}{ }^{d f i}$ is therefore given by $[17,22]$ :

$\beta_{P}{ }^{d f i}=(2 e \alpha c M / 3)\left(\right.$ T uP $\left.^{\text {Henry }} /\left|Z_{S}\right| b_{S}{ }^{3}\right)\left[\left(\varepsilon_{0}-\varepsilon_{\infty}\right) \varepsilon_{0}{ }^{-2}\right]\left|\left(f_{M}{ }^{3}-4.808\right)\right| Z_{S}|+6.58| ; f_{M}=b_{S} / R_{g, M}$

With, according to Eqs. (24 -28): uP $_{P}^{\text {Henry }}=\left(e\left|Z_{S}\right| \alpha_{C M} / 6 \pi \eta C^{\prime}{ }_{A P}\right)$. Now, if we replace the relaxation time $\mathrm{T}$ by its Debye's expression: $\tau=\left(6 \pi \eta R_{w}{ }^{3} / k_{B} T\right)$, with $L_{B}=e^{2} / \varepsilon_{0} k_{B} T$, the general explicit expression of $\beta_{P}{ }^{\text {dfi }}$ becomes: 
$\beta_{P}^{d f i}=(2 / 3) \alpha_{C M}{ }^{2}\left(R_{w} / b_{S}\right)^{3}\left(L_{B} / C_{A P}^{\prime}\right)\left[1-\varepsilon_{\infty} / \varepsilon_{0}\right]\left|\left(f_{M}^{3}-4.808\right)\right| Z_{S}|+6.58|$

In fact, the dielectric friction undergone by each spherical group can be decomposed into a self contribution due to the polarization induced by its own charge $\alpha_{\mathrm{CM}}$ and into a crossed contribution due to the polarization caused by the other $\mid Z_{S}$ -1 | spherical groups (interference effect indicated by the index "i" in $\beta_{P}{ }^{d f i}$ ). Notice however that, if the distance: $b_{S}=L_{S} /\left|Z_{S}\right|$, between two successive charged groups is sufficiently large, $\mathrm{f}_{\mathrm{M}}^{-1} \rightarrow 0$ and the interference effect vanishes.

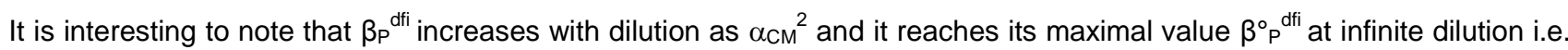
when $\alpha_{\mathrm{CM}} \rightarrow 1$ (Ostwald) and $\mathrm{C}_{\mathrm{AP}} \rightarrow<\mathrm{RP}_{\mathrm{P}}>$ :

$\beta^{\circ}{ }_{P}^{d f i}=(2 / 3)\left(R_{w} / b_{S}\right)^{3}\left(L_{B} /<R_{P}>\right)\left[1-\varepsilon_{\infty} / \varepsilon_{0}\right]\left|\left(f_{M}{ }^{3}-4.808\right)\right| Z_{S}|+6.58|$

Consequently, according to Eqs. (29, 33 and 34 ), the two friction coefficients: $\beta_{\mathrm{ir}}{ }^{\mathrm{P}}$ (ionic friction) and $\beta_{\mathrm{P}}{ }^{\mathrm{dfi}}$ (dielectric friction), can be written respectively in terms of an ionic parameter $B$ and of a dielectric parameter $\mathbf{C}_{\mathrm{M}}$ as follows:

$\beta_{\mathrm{ir}}{ }^{\mathrm{P}}=\alpha_{\mathrm{CM}} \mathrm{B} ; \quad ; \quad \beta_{\mathrm{P}}{ }^{\mathrm{dfi}}=\alpha_{\mathrm{CM}}{ }^{2} \mathbf{C}_{\mathrm{M}}$

With:

$B=\left|Z_{S} Z_{M}\right| L_{B}\left(3 d_{P}^{2}+L_{S}^{2} / 4\right) /\left[18\left(d_{P}^{2}+L_{S}^{2} / 4\right)^{3 / 2}\right]$ and $C_{M} \approx \beta_{P}^{\circ}{ }^{d f i}\left(<R_{P}>/ C_{A P}^{\prime}\right)$

Note that the dependence of $\alpha_{C M}$ and $C_{M}$ with the nature of the counter-ion is indicated by the index $M$.

In the other hand, the term $\left(\alpha_{C M} \lambda_{P}{ }^{\circ H y d}-\Delta \lambda_{P}{ }^{\text {el }}\right)$ expressing in Eq.23 the hydrodynamic contribution and the electrophoretic contribution can also be written in terms of the hydrodynamic parameter $\mathbf{A}_{M}$ defined as follows:

$\left(\alpha_{C M} \lambda_{P}{ }^{\circ H y d}-\Delta \lambda_{P}{ }^{e l}\right)=\alpha_{C M}\left|Z_{S}\right| F e / 6 \pi \eta C^{\prime}{ }_{A P} \equiv \alpha_{C M} A_{M}$

The introduction of Eqs. (36 and 38) into Eq. 23 leads to the following "Universal form" of the expression of the conductibility $\lambda_{P, M}$ of the stretched polyion:

$\lambda_{P, M}=\alpha_{C M} A_{M} /\left[1+\alpha_{C M} B+\alpha_{C M}^{2} C_{M}\right]$

We have used previously this general form in order to distinguish between the Manning's regime for which the degree $\alpha_{\mathrm{CM}}$ remains quasi constant, and the Ostwald's regime for which $\lambda_{P, M}$ varies more appreciably with the dilution process via $\alpha_{C M}$ $[17,22]$.

In this paper we will use this expression in order to explain the possible specific dependence of the conductibility $\lambda_{P, M}$ of the polyion with the nature of the counter-ions. Indeed, According to Eq. 39, this specificity can result from the dependence with the nature of the counter-ion $M$, of $\alpha_{C M}, \mathbf{C}_{M}$ and $\mathbf{A}_{M}$ parameters relating to respectively the process of ionic condensation, the dielectric friction (via the specific group radius $R_{g, M}$ ), and the hydrodynamic-electrophoretic friction.

Only the two parameters: $\alpha_{C M}$ and $\mathbf{A}_{M}$ are considered in the Vink's approach. Moreover, the comparison for each concentration between the $\alpha_{\mathrm{CM}}$ of the different counter-ions given in table 3 , show that organic cations $\mathrm{Et}_{4} \mathrm{~N}^{+}$and $\mathrm{Bu}_{4} \mathrm{~N}^{+}$ present a certain specific association with the charged groups of the PSS polyion due to their hydrophobic character. In contrast, ionic condensation of the alkaline cations $\mathrm{Li}^{+}, \mathrm{K}^{+}$and $\mathrm{Na}^{+}$seems to be quasi independent on the nature of the counter-ion and their mean value is equal to the Manning value which is about 0.35 . Consequently, according to Vink's interpretation, the important deviations: $\Delta \lambda \equiv\left(\lambda_{P, M}-\lambda_{P, M^{\prime}}\right)$ observed between two polyion conductibilities of any couple of counter-ions $M$ and $M$ ' must be interpreted in terms of hydrodynamic friction parameter $\mathbf{A}_{M}$ (via the specific cylindrical radius $R_{C M}=R_{C}+R_{M}+n R_{w}$ ). In contrast, it is obvious that this specificity disappears in the case of the Manning's Model. In the following paragraph, we will show that in the case of stretched polyion, the most important factor at the origin of the specificity of $\lambda_{P, M}$ to $M$ comes rather from the high sensitivity of the dielectric parameter $\mathbf{C}_{M}$ to the local structure parameters characterizing the surrounding of each specific group of apparent radius $R_{g, M}$. 


\subsection{Interpretation of the dependence of the conductibility of PSS with the nature of the counter-ion.}

In this section we will calculate for each counter-ion $M$ of concentration $C_{M}^{\circ}$ the different specific parameters: $R_{C M}, A_{M}, C_{M}$ and $R_{g, M}$ defined previously, in order to interpret the dependence of the conductibility of PSS with the nature of each counter-ion.

Table 5 gives the different ionic radii $R_{M}$ and the different specific cylindrical radii $R_{C M}=R_{C}+R_{M}+R_{w}$ relating to the counter-ions $\mathrm{Li}^{+}, \mathrm{K}^{+}, \mathrm{Na}^{+}, \mathrm{Et}_{4} \mathrm{~N}^{+}$and $\mathrm{Bu}_{4} \mathrm{~N}^{+}$, using $\mathrm{R}_{\mathrm{C}}=6.85 \mathrm{~A}^{\circ}$ [17] (radius of the PSS chain) and $\mathrm{R}_{\mathrm{w}}=1.4 \mathrm{~A}^{\circ}$ (radius of the water molecule).

Table 5. Radii $\mathrm{R}_{\mathrm{M}}$ and specific cylindrical radii $\mathrm{R}_{\mathrm{CM}}$ relating to the counter-ions $\mathrm{Li}^{+}, \mathrm{K}^{+}, \mathrm{Na}^{+}, \mathrm{Et}_{4} \mathrm{~N}^{+}$and $\mathrm{Bu}_{4} \mathrm{~N}^{+}$.

\begin{tabular}{|c|c|c|c|c|c|}
\hline & $\mathrm{K}^{+}$ & $\mathrm{Na}^{+}$ & $\mathrm{Li}^{+}$ & $\mathrm{Et}_{4} \mathrm{~N}^{+}$ & $\mathrm{Bu}_{4} \mathrm{~N}^{+}$ \\
\hline $\mathrm{R}_{\mathrm{M}}\left(\mathrm{A}^{\circ}\right)$ & 1.33 & 0.98 & 0.68 & 4.0 & 4.94 \\
\hline $\mathrm{R}_{\mathrm{CM}}\left(\mathrm{A}^{\circ}\right)$ & 8.18 & 9.23 & 10.33 & 10.85 & 11.79 \\
\hline
\end{tabular}

Calculation of the specific empirical parameters $\mathbf{C}_{\mathrm{M}}$ which are related to the dielectric friction is achieved according to the following equation after recombination of Eq. 39:

$\mathbf{C}_{\mathrm{M}}=\left[\alpha_{\mathrm{CM}} \mathrm{A}_{\mathrm{M}}-\lambda_{\mathrm{P}, \mathrm{M}}\left(1+\beta_{\mathrm{ir}}{ }^{\mathrm{P}}\right)\right] / \alpha_{\mathrm{CM}}{ }^{2} \lambda_{\mathrm{P}, \mathrm{M}}$

The $\lambda_{P, M}$ indicates the experimental conductibility of PSS in presence of the counter-ion "M" (see table 4a). The expression of the hydrodynamic-electrophoretic parameter $A_{M}$ is extracted from Eq. (38).

\section{$\mathbf{A}_{M}=\left|Z_{S}\right| F e / 6 \pi \eta C^{\prime}{ }_{A P}$}

The capacity $C_{A P}^{\prime}$ is defined by Eqs. $(25,26,27$ and 28). Tables 6 gives the variations with the total ionic concentration $C^{\circ}{ }_{M}$ of the hydrodynamic-electrophoretic parameters " $\mathbf{A}_{M}$ " and the dielectric parameters $\mathbf{C}_{M}$ relating to Polystyrene Sulphonate KPSS, NaPSS, LiPSS, Et ${ }_{4} N P S S$ and $\mathrm{Bu}_{4}$ NPSS in water at $25^{\circ} \mathrm{C}$.

Table 6. Variations with counter-ions concentration $\mathrm{C}_{\mathrm{M}}{ }^{+}$of the hydrodynamic-electrophoretic parameters "A $\mathbf{A}_{M}$ " and the dielectric parameters $\mathbf{C}_{\mathrm{M}}$ relating to Polystyrene Sulphonate: KPSS, NaPSS, LiPSS, Et $t_{4}$ NPSS and Bu ${ }_{4}$ NPSS in water at $25^{\circ} \mathrm{C}$.

\begin{tabular}{|c|c|c|c|c|c|c|c|c|c|c|}
\hline $\begin{array}{c}\mathrm{C}^{\circ} \mathrm{M}^{+} \\
\mathrm{mol.}^{-1}\end{array}$ & $\mathbf{A}_{\mathrm{K}}$ & $\mathbf{C}_{\mathrm{K}}$ & $\mathbf{A}_{\mathrm{Na}}$ & $\mathbf{C}_{\mathrm{Na}}$ & $\mathbf{A}_{\mathrm{Li}}$ & $\mathbf{C}_{\mathrm{Li}}$ & $\mathbf{A}_{\mathrm{Et} 4 \mathrm{~N}}$ & $\mathbf{C}_{\mathrm{Et} 4 \mathrm{~N}}$ & $\mathbf{A}_{\mathrm{Bu} 4 \mathrm{~N}}$ & $\mathbf{C}_{\mathrm{Bu} 4 \mathrm{~N}}$ \\
\hline $510^{-4}$ & 274.115 & 2.628 & 268.103 & 2.147 & 258.606 & 2.885 & 258.125 & 4.710 & 254.202 & 6.743 \\
\hline $110^{-3}$ & 249.068 & 1.961 & 242.303 & 1.754 & 232.975 & 2.381 & 233.317 & 3.996 & 228.801 & 6.421 \\
\hline $1.510^{-3}$ & 234.376 & 1.674 & 227.029 & 1.670 & 217.822 & 2.239 & 218.800 & 3.724 & 213.916 & 6.469 \\
\hline $210^{-3}$ & 223.902 & 1.527 & 216.184 & 1.651 & 207.068 & 2.194 & 208.495 & 3.595 & 203.495 & 6.523 \\
\hline $2.510^{-3}$ & 215.723 & 1.444 & 207.883 & 1.606 & 198.849 & 2.144 & 200.502 & 3.506 & 195.637 & 6.459 \\
\hline $310^{-3}$ & 208.990 & 1.391 & 201.275 & 1.497 & 192.292 & 2.060 & 193.969 & 3.418 & 189.486 & 6.219 \\
\hline $3.510^{-3}$ & 203.255 & 1.341 & 195.907 & 1.301 & 186.992 & 1.899 & 188.445 & 3.308 & 184.609 & 5.768 \\
\hline
\end{tabular}

According to this table we can conclude that:

- The hydrodynamic-electrophoretic friction increases with the $\mathrm{R}_{\mathrm{CM}}$ radius of the condensed counter-ion, from $\mathrm{K}^{+}$to $\mathrm{Bu}_{4} \mathrm{~N}^{+}$(see table 5). However, this increase cannot, completely explain the great dependence of the conductibility of the polyion with the nature of its counter-ion. 
The dielectric friction is practically the same for $\mathrm{Na}^{+}$and $\mathrm{K}^{+}$, it undergoes a weak increase for $\mathrm{Li}^{+}$and it increases by a factor two for $\mathrm{Et}_{4} \mathrm{~N}^{+}$and by a factor three for the $\mathrm{Bu}_{4} \mathrm{~N}^{+}$.

In order to interpret the dependence of $\mathbf{C}_{M}$ with the nature of the counter-ions, we will express the parameter $\mathbf{C}_{M}$ in terms of the physical parameters influencing the dielectric friction effect (i.e. the dielectric relaxation time $\mathrm{T}$, the local dielectric permittivities $\varepsilon_{0}$ and $\varepsilon_{\infty}$ around each group). Combination of Eqs. (33 and 36), leads to:

$\mathbf{C}_{M}=\left(e^{2} / 9 \pi \eta\right)\left(1 / C_{A P}^{\prime} b_{S}^{3}\right)\left[\tau\left(\varepsilon_{0}-\varepsilon_{\infty}\right) \varepsilon_{o}^{-2}\right]\left|\left(f_{M}{ }^{3}-4.808\right)\right| Z_{S}|+6.58| ; f_{M}=b_{S} / R_{g, M}$

Eq. 42 can be recombined in order to express the group radius $R_{g, M}$ as a function of $T$ :

$\mathrm{R}_{\mathrm{g}, \mathrm{M}}=\mathrm{b}_{\mathrm{S}}\left[9 \pi \eta \mathbf{C}_{\mathrm{M}} \mathrm{C}_{\mathrm{AP}}{ }_{\mathrm{APS}}{ }^{3} \varepsilon_{\mathrm{o}}{ }^{2}\left\{\mathrm{e}^{2}\left|\mathrm{Z}_{\mathrm{S}}\right| \mathrm{T}\left(\varepsilon_{\mathrm{o}}-\varepsilon_{\infty}\right)\right\}^{-1}+4.808-6.58 /\left|\mathrm{Z}_{\mathrm{S}}\right|\right]^{-1 / 3}$

Calculation of $R_{g, M}$ needs the knowledge of the relaxation time $\mathrm{t}$ of water molecules, the static permittivity $\varepsilon_{0}$ and the highfrequency permittivity $\varepsilon_{\infty}$ of water. Experimental values of $\mathrm{T}, \varepsilon_{0}$ and $\varepsilon_{\infty}$ for pure water at $298.15 \mathrm{~K}$ are: $\varepsilon_{0}=78.3, \varepsilon_{\infty}=4.49$ and $\mathrm{T}=8.32 \mathrm{ps}$ [24]. Note that this last value is less than the value estimated according to the Debye's expression: $\tau=\left(6 \pi \eta R_{w}{ }^{3} / \mathrm{k}_{\mathrm{B}} \mathrm{T}\right)=11.187 \mathrm{ps}$ at $298.15 \mathrm{~K}$. Table 7 gives the variations with the total ionic concentration $C^{\circ} \mathrm{M}$ of the calculated group radii $R_{g, M}$ in $A^{\circ}$, relating to Polystyrene Sulphonate KPSS, NaPSS, LiPSS, Et ${ }_{4} N P S S$ and Bu ${ }_{4} N P S S$ in water at $25^{\circ} \mathrm{C}$. One indicates by $\left\langle R_{g}, M\right\rangle$, the mean group radius of the polyion PSS partially condensed by counter-ions $M$. The Examination of these results shows that the obtained mean radii: $\left\langle R_{g}, M\right\rangle$, depend on the nature of the counterions and are in general greater than the structural group radius of the PSS polyion which is equal to $R_{g}=b_{S} / 2=1.25 A^{\circ}$. Deviation of $<R_{g}, M>$ from $R_{g}$ can be interpreted by replacing $T$ and $\varepsilon_{0}$ in Eq. 43 by their "local" values $T^{\prime}$ and $\varepsilon_{0}^{\prime}$. Indeed, the relaxation time of water molecules around the polyion PSS and its counter-ions is different from its bulk value $\mathrm{T}$, so that $T^{\prime}$ is in fact a mean value $<T$. In same way, $\varepsilon_{0}^{\prime}<\varepsilon_{0}$ because of the dielectric saturation effect in the surrounding of the polyion and the counter-ions. It is obvious that the local structure of water depend on the nature of the condensed counterions, this could explain the specificity of the dielectric parameter $\mathbf{C}_{\mathrm{M}}$ to the nature of counter-ions via T' and $\varepsilon^{\prime}$.

Table 7. Variations with counter-ions concentration $C^{\circ}{ }_{M}^{+}$of the the group radii $R_{g}, M$ in $A^{\circ}$ and $<R_{g, M}>$ are the mean group radii, relating to Polystyrene Sulphonate: KPSS, NaPSS, LiPSS, Et $\mathrm{NPSS}$ and $\mathrm{Bu}_{4} \mathrm{NPSS}$ in water at $25^{\circ} \mathrm{C}$.

\begin{tabular}{|c|c|c|c|c|c|}
\hline $\begin{array}{c}\mathrm{C}^{\circ} \mathrm{M}^{+} \\
\mathrm{mol.}^{-1}\end{array}$ & $\mathrm{Rg}, \mathrm{K}$ & $\mathrm{Rg}, \mathrm{Na}$ & $\mathrm{Rg}, \mathrm{Li}$ & $\mathrm{Rg}, \mathrm{Et4N}$ & $\mathrm{Rg}_{, \mathrm{Bu} 4 \mathrm{~N}}$ \\
\hline $510^{-4}$ & 1.350 & 1.370 & 1.335 & 1.265 & 1.203 \\
\hline $110^{-3}$ & 1.372 & 1.378 & 1.345 & 1.275 & 1.193 \\
\hline $1.510^{-3}$ & 1.381 & 1.379 & 1.346 & 1.276 & 1.178 \\
\hline $210^{-3}$ & 1.385 & 1.375 & 1.343 & 1.274 & 1.167 \\
\hline $2.510^{-3}$ & 1.387 & 1.375 & 1.341 & 1.272 & 1.161 \\
\hline $310^{-3}$ & 1.388 & 1.378 & 1.342 & 1.271 & 1.162 \\
\hline $3.510^{-3}$ & 1.389 & 1.388 & 1.348 & 1.272 & 1.162 \\
\hline$<\mathrm{R}_{\mathrm{g}, \mathrm{M}}>$ & $\mathbf{1 . 3 7 8}$ & $\mathbf{1 . 3 7 7}$ & $\mathbf{1 . 3 4 3}$ & $\mathbf{1 . 2 7 2}$ & $\mathbf{1 . 1 7 5}$ \\
\hline
\end{tabular}

\section{CONCLUSION}

The Manning's model is not able to explain the dependence of the conductibility of the PSS polyion with the nature of the counter-ions $\mathrm{M}$, because the counter-ions are assumed as punctual charges. However, predictions according to this model of both the degree of condensation and the ionic friction coefficient $\left(\alpha \approx 0.35\right.$ and $\left.\beta_{\text {ir }} \approx 0.13\right)$ are acceptable in particular for the alkaline cations $\left(\mathrm{Li}^{+}, \mathrm{Na}^{+}\right.$and $\left.\mathrm{K}^{+}\right)$, but with a small observed negative deviation $(\alpha \approx 0.31)$ for the two hydrophobic cations $\left(\mathrm{Et}_{4} \mathrm{~N}^{+}\right.$and $\left.\mathrm{Bu}_{4} \mathrm{~N}^{+}\right)$.

In contrast, Vink has suggested a more realistic qualitative description in taking into account of the cylindrical radius $R_{C}$ of the polyion and the size $R_{M}$ of the condensed counter-ions, so that the hydrodynamic friction on the polyion increases with the minimal distance of approach $\left(R_{C, M}=R_{C}+R_{M}+n R_{w}\right)$ between a specific condensed counter-ion and a charged polyion group.

In this work, we have used a recent model in which the stretched PSS polyion is represented by a chain of successive charged spheres, partially condensed by the counter-ions, in order to quantify the dependence of the hydrodynamic 
friction on PSS polyion with the size of alkaline cations $\left(\mathrm{Li}^{+}, \mathrm{Na}^{+}\right.$and $\left.\mathrm{K}^{+}\right)$and with the size of two hydrophobic cations $\left(\mathrm{Et}_{4} \mathrm{~N}^{+}\right.$and $\left.\mathrm{Bu}_{4} \mathrm{~N}^{+}\right)$, and we have found that the moderate increasing of this friction with the $\mathrm{R}_{\mathrm{CM}}$ distance from $\mathrm{K}^{+}$to $\mathrm{Bu}_{4} \mathrm{~N}^{+}$, cannot completely explain the important decrease (of about $35 \%$ from $\mathrm{K}^{+}$to $\mathrm{Bu}_{4} \mathrm{~N}^{+}$) of the conductibility $\left(\lambda_{\mathrm{PSS}, \mathrm{M}}\right.$ ) of the PSS polyion with the size $R_{M}$ of its condensed counter-ion $M$. Consequently, we have proposed a supplementary explanation to the high dependence of the mobility of the polyion with the nature of its counter-ions, by taking into account of the translational dielectric friction on the moving polyion due to the time dependent polarization of its surrounding water molecules. This supplementary friction which is in the case of this model, the most important friction effect, can be evaluated quantitatively in terms of the specific dielectric parameter $\mathbf{C}_{M}$ which is function on the relaxation time $\mathrm{T}$ of water molecules, the static permittivity $\varepsilon_{0}$ and the high-frequency permittivity $\varepsilon_{\infty}$ of water. Now, as these physical parameters are sensitive to the local structure of water surrounding the polyions, and in turn, this local structure depends on the nature of the condensed counter-ions, we suggested that the specificity of the parameter $\mathbf{C}_{\mathrm{M}}$ could explain the high dependence of the mobility of the polyion with the nature of its counter-ions.

\section{REFERENCES}

[1] M. Muthukumar, "Dynamics of polyelectrolyte solutions," Journal Chemical Physics. (1997), 107, 2619-2635.

[2] E. Sélégny, "Polyelectrolytes”, D. Reildel Publishing Company. Dordrecht-Holland. Boston-U.S.A, (1974).

[3] G. S. Manning, "Limiting Laws for the conductance of the rod model of a salt-free polyelectrolyte solution," Journal of Physical Chemistry. (1975), 79, 262-265.

[4] G. S. Manning, "Limiting Laws and counter-ion condensation in polyelectrolyte solutions. 7. Electrophoretic mobility and conductance," Journal of Physical Chemistry. (1981), 85, 1506-1515.

[5] A. V. Dobrynin, M. Rubinstein. "Theory of Polyelectrolytes in solutions and at surfaces," Progress in Polymer Science. (2005), 30, 1049-1118.

[6] J. M'halla, "Polelectrolytic conductance. Limiting laws in conformity with the principles of equilibrium and nonequilibrium thermodynamics. Interdependence between conformation, condensation and dielectric friction,"Journal of Molecular Liquids. (1999), 82, 183-218.

[7] J. M'halla, R. Besbes, R. Bouazzi, S. Boughammoura, "About the singular behavior of the ionic condensation of sodium chondroitin sulfate: Conductivity study in water and water-dioxane mixture," Journal Chemical Physics. (2006), 321, 10-24.

[8] J. M'halla, R. Besbes, R. Bouazzi, S. Boughammoura, "Ionic condensation of sodium chondroitin sulfate in waterdioxane mixture," Journal of Molecular Liquids. (2007), 130, 59-69.

[9] N. V. Brilliantov, D.V. Kuznetsov, R. Klein, "Chain collapse counterion condensation in dilute polyelectrolyte solutions,"Physical Review Letters. (1998), 81, 1433-1436.

[10] C. Wandrey, "Concentration Regimes in Polyelectrolyte Solutions," Langmuir. (1999), 15, 4069-4075.

[11] H. Vink, "Conductivity of Polyelectrolyte in Very Dilute Solutions," Journal of Chemical Society, Faraday Transactions. 1. (1981), 77, 2439-2449.

[12] H. Vink, "A New Modified Hittorf Method for the Determination of Transport Numbers in Polyelectrolyte solutions," Journal of Chemical Society, Faraday Transactions 1. (1984), 80, 1297 - 1304.

[13] H. Vink, "Studies of Electrical Transport Processes in Polyelectrolyte solutions," Journal of Chemical Society, Faraday Transactions 1. (1989), 85, 699-709.

[14] R. A.Robinson, R.H.Stokes, “Electrolyte Solutions," Butterworths scientific publications, London, (1959).

[15] R. Zwanzig, "Dielectric Friction on a Moving Ion,” Journal Chemical Physics. (1963), 38, 1603-1605.

[16] S. Boughammoura, J. M'halla, "Estimation of the "hydrophobic reactivity" of SDS micelles by the use of BPh anions," Journal of Molecular Liquids. (2012), 175, 148-161.

[17] A. Ghazouani, S. Boughammoura, J. M'halla," Studies of Electrolytic Conductivity of Some Polyelectrolyte Solutions. Importance of the Dielectric Friction Effect at High Dilution ", Journal of Chemistry. (2012), 2013, 1-15.

[18] J. M'halla, S. Boughammoura, "Translation dielectric friction and mobility of ellipsoidal polyions," Journal of Molecular Liquids. (2010), 157, 89-101.

[19] J. B. Hubbard, J. F. Douglas, "Hydrodynamic friction of arbitrarily shaped Brownian particles," Physical Review E.

[20] L. Blum, "Mean spherical model for asymmetric electrolytes," Journal Molecular Physics. (1975), 30, $1529-1535$.

(1993), 47, 2983-2986.

[21] P.G. Wolynes, "Molecular theory of solvated ion dynamics," Journal of Chemical Physics. (1978), 68, 473-483. 
[22] J. M'halla, S. Boughammoura, A. Ghazouani, "Sharp decrease of the dielectric friction on polyions during conformation transition from pearl-chain to coiled shapes," $32^{\text {iéme }}$ International conference on solution chemistry-ICSI, la Grande Motte, France, (2011).

[23] J. B. Hubbard; L. Onsager, " Dielectric dispersion and dielectric friction in electrolyte solutions I and II " J. Chem. Phys. (1977) , 67, 4850; J. B. Hubbard, J. Chem. Phys. (1978), 68, 1649.

[24] P. Turq, J. Barthel and M. Chemla, "Transport, Relaxation and Kinetic Processes in Electrolyte Solutions"; Ed Springer-Verlag Berlin Heidelberg, (1992). 